\title{
Applications of Fiber Optic Coupled-Grazing Angle Probe Reflection-Absorption FTIR Spectroscopy
}

\author{
Oliva M. Primera-Pedrozo, Leonardo C. Pacheco-Londoño and \\ Samuel P. Hernandez-Rivera \\ ALERT DHS Center of Excellence for Explosives \\ Center for Chemical Sensors Development \\ Department of Chemistry \\ University of Puerto Rico-Mayagüez \\ PO Box 9000, Mayagüez, PR, 00681
}

Puerto Rico

\section{Introduction}

The recent increase in attention of detection of chemical threats, explosives and narcotics has led to the development of instruments and sensors that can be effective in a variety of operating environments. Various approaches can be used for in situ analysis of explosives, including the widely used technique, Ion Mobility Spectrometry (IMS). The major advantages of IMS are its sensitivity in the picogram range, its continuous real time monitoring capability, its reasonable price due to instrumental simplicity and the ease of automation (Salleras, 1995). A main disadvantage of IMS is its limited linear range and that it cannot be used for quantitative analysis (Salleras, 1995). It is relatively easy to overload an IMS and, therefore, sample size must be controlled with care (Brambilla, 1997). Another weakness is the response variation that occurs with different background gas compositions and with different sample compositions (Salleras, 1995). However, spectroscopic techniques have the potential to afford the best selectivity for explosives. The infrared spectra of molecules can provide an information-rich fingerprint that allows for near unambiguous identification. A few years ago, direct detection by infrared absorption spectroscopy was not possible because of the limited sensitivity of this method. Fourier Transform Infrared Reflection Absorption Spectroscopy (IRRAS), operating at the grazing-angle, is the most sensitive optical absorption technique available for measuring low concentrations of chemical compounds adhered to reflective surfaces such as metals (Griffiths, 1986). The disadvantage of conventional spectroscopic techniques for applications such as explosives detection is that the test materials must be placed physically within the spectrometer's sample compartment for measurement. FT-IRRAS combined with grazing angle probe (GAP) can now be used outside the boundaries of the sample compartment. Fiber-optic cables (FOCs) that transmit in the mid-IR (MIR) range have made it possible to develop a range of spectroscopic probes for in situ analysis (Melling, 2001; Melling, 2002; Mehta, 2003; Bacci, 2001). Thus, FTIR spectroscopy can now be effectively used outside the confinement 
of the sample compartment, making it available for field work (Mizaikoff, 2002). The attractive features of this technique include portability, simple design and rugged design, high sensitivity and short analysis time. These features lead to potential uses of Mid FTIR for airport screening and within the military.

Sample preparation methodology constitutes a critical a step in the detection scheme pursed because a uniformly covered, thin film is needed for preparation of the standard samples on which precision relies on. Several approaches have been used in the lab for sample preparation including: standard preparation using an airbrush aerosol spray, sample smearing and direct transfer from solutions using micropipettes (Primera-Pedrozo, 2004). In the smearing method $20 \mu \mathrm{L}$ aliquots of standard solutions were deposited over the plate then the solution is spread using a Teflon sheet. Smearing transfer method has led to detect TATP over stainless steel surface. This transfer method let to detect and quantify TATP for first time on metallic surfaces. Despite the fact of tendency towards sublimation of TATP, a limiting value of $8 \mu \mathrm{g} / \mathrm{cm}^{2}$ could be detected. Samples ranging from micrograms $/ \mathrm{cm}^{2}$ to nanograms $/ \mathrm{cm}^{2}$ of 2,6-dinitrotuelene (DNT), 2,4,6-trinitrotoluene (TNT), pentaerythritol tetranitrate (PETN), nitroglycerine (NG) and triacetone triperoxide (TATP) have been detected using this new method of deposition. A smearing deposition was used for depositing the target explosives over substrates to be used as standards. The sample transfer method gave good sample distribution, reduced sample loss on transfer and was easy to manipulate giving good reproducible distributions (Primera-Pedrozo, 2004; PrimeraPedrozo, 2009; Primera-Pedrozo, 2010; Pacheco-Londoño, 2010). Although, the smearing technique has given good results for explosives detection, many samples are needed for sample preparation transfer method because it depends on human error since the sample is placed using a piece of Teflon sheet and is distributed with the hands on the surface and sometimes good distribution is not found. In this case other samples have to be prepared. Another disadvantage of this transfer method is solvent interference since various solvents are adhered to the stainless steel plated producing poor distribution of the material over the surfaces. The use of slow evaporating solvents makes the sample preparation more complicated. For these reasons the development of an automatic method for explosives transfers on the surfaces must be devised. Thermal ink jet (TIJ) was selected as transfer technique to avoid human errors during preparation of standards and to decrease the time for sample preparation. In thermal ink jet a thin film resistor superheats less that $0.5 \%$ of the fluid in the chamber to form a gas bubble. This bubble rapidly expands (less than ten microseconds) and forces a drop to be ejected through an orifice (Beeson, 1998).

When comparing the inkjet based method of sample transfer to the smearing method used in previous works (Primera-Pedrozo, 2004), the former has notable advantages. The loading concentration of the sample on the surface can be controlled by varying parameters such as: number of passes, dispensing frequency, applied energy, and pen architecture. Precise delivery of the number of droplets with known volume and concentration controls the mass deposited. Also only one solution needs to be used, avoiding dilutions that can increase the analytical errors.

\section{Description of methodology}

FOC-GAP FTIR spectroscopy has made possible to develop new methods for detection of traces of chemical compounds on surfaces. Thermal inkjet (TIJ) technology is able to deposit very small amounts of chemical compounds, including energetic materials, in a specific 
location on a surface (Primera-Pedrozo, 2005). Aliquots of TNT and RDX solutions were deposited on stainless steel film. A thin coating of the explosives can be produced by controlling the concentration of TNT or RDX, the number of drops dispensed and the distribution of drops on the surface. A Vector 22, a Bruker Optics FTIR fiber coupled to a Remspec Corp. Grazing Angle Probe head was used for the experiments. The spectra were recorded at $4 \mathrm{~cm}^{-1}$ resolution and 50 scans. The results of the experiments gave intense absorption bands in the fingerprint region of the infrared spectra that were used for quantification. Chemometrics routines were applied for enhancing quantitative analysis.

The sample analysis setup is schematically presented in Fig. 1. A Remspec mid-IR grazing angle probe was used to collect the spectra. The grazing-angle head uses carefully aligned mirrors to deliver the mid-IR beam to the sample surface at the grazing angle (approximately $80^{\circ}$ from normal), to collect the reflected beam, and to return it to a mid-IR detector (in this case, external liquid nitrogen cooled MCT detector). The signal is delivered from the spectrometer to the head by IR transmitting fiber optic cables. The grazing angle accessory is connected to the external beam port of the Bruker Vector 22 spectrometer by a $1.5 \mathrm{~m}, 19$-fiber chalcogenide glass optical bundle in the As-Se-Te system, which transmits throughout the mid-IR with the exception of a strong H-Se absorbance band at $2200 \mathrm{~cm}^{-1}$. The IR footprint produced by the grazing angle probe is elliptical with the intensity decaying from the middle towards the edges. The specially configured head illuminates a large spot on the sample surface. The spot is an ellipse 1 inch by six inches that is defined by a Gaussian distribution with a center spot about $1 / 8$ inch by an inch. The electric signal from the MCT is delivered to the FTIR using an amplifier.

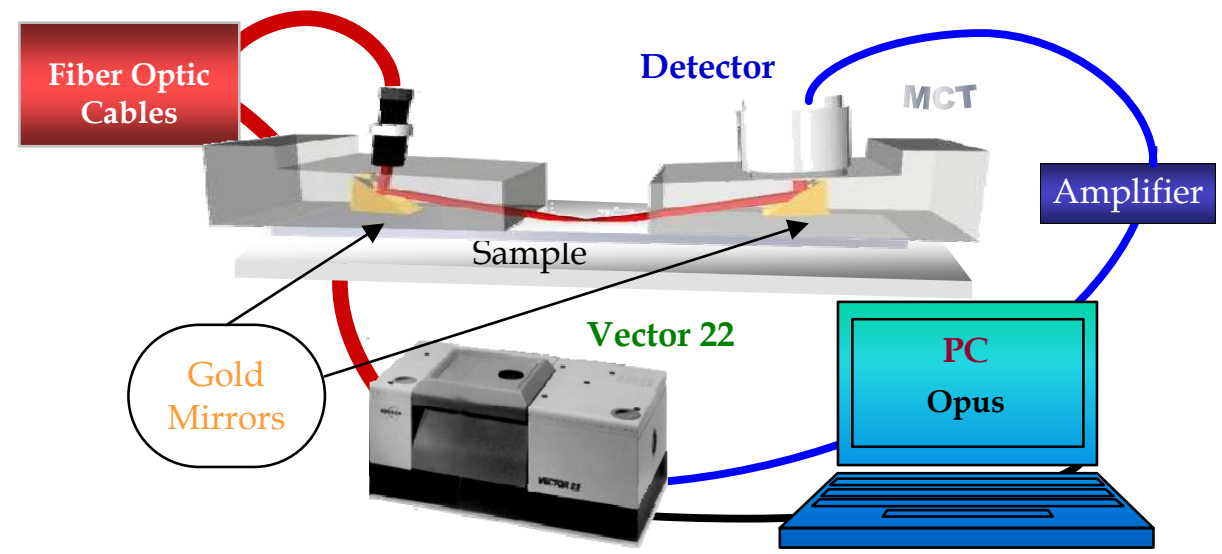

Fig. 1. Experimental setup for Fiber Optic Coupled-Grazing Angle Probe FTIR

\section{Evaluation of samples and standards}

FOP-GAP FTIR absorption-reflection spectroscopy may be successfully implemented in assessing sample loading distribution of solids deposited on substrates (Primera-Pedrozo, 2008; Primera-Pedrozo, 2009). Two methods were used to prepare the samples by depositing the analytes onto the test surfaces: sample smearing and thermal inkjet transfer. Stainless steel (SS, non-magnetic, type 316) metal sheets with an effective or area for coverage of 46.3 $\mathrm{cm}^{2}(3 \mathrm{~cm} \times 15.4 \mathrm{~cm})$ were used. The plates were cleaned with HPLC grade methanol and 
air-dried at room temperature before the experiments. Aliquots of $20 \mu \mathrm{L}$ of standard solutions were placed at one side of the SS plate. A Teflon sheet was inclined towards the right or left and the smearing was done quickly. Fig. 2-a illustrates how the smearing is done.

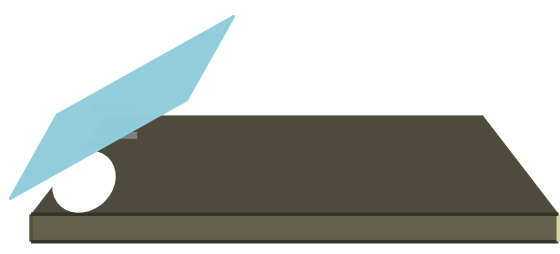

(a)

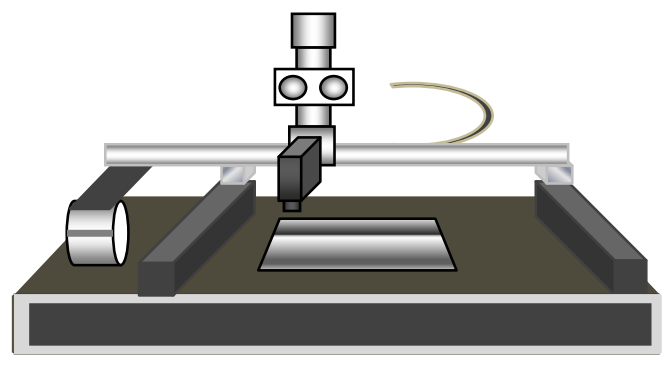

(b)

Fig. 2. Methods used for transferring a solid sample onto a substrate: (a) TIJ; (b) sample smearing

This method is rapid and easily executed without specialized equipment. The amount is readily controlled and can be calculated without the need for an independent analysis. Once the solvent had evaporated, the spectrum of the sample was collected immediately. Solutions were dispensed using an ImTech Imaging System model I-Jet 312S, (ImTech, OR, USA) equipped with a HP 51645A inkjet cartridge, illustrated in Fig. 2-b. Aliquots of $10 \mathrm{~mL}$ were placed into the inkjet cartridge and the backpressure was set to 3 inches of water using an external backpressure controller. The solutions were dispensed over stainless plates at zero dot spacing (space between drops using HP ink) using a printing resolution of 600 dots per inch (dpi). Once the solvent had evaporated, the spectrum of the sample was collected.

\section{Cleaning validation of pharmaceutical batch reactors}

FOC-GAP FTIR spectroscopy can be used in cleaning validation applications for active pharmaceutical agents on metallic surfaces (Mirza, 1999); Mehta, 2002; Primera-Pedrozo, 2005-b; Fierro-Mercado, 2010). A method based on smearing a known amount of the sample in solution was used for preparing samples and standards to develop cleaning validation methodologies using IR spectroscopy. The samples were deposited on the surface using smearing transfer method. Using this method ibuprofen was detected on stainless steel plates, a common material on pharmaceuticals reactors. This new technology combining to smearing can decrease the consuming time in cleaning validation process, being advantageous in an in process laboratory. Detection limit for this compound was $0.5 \mu \mathrm{g} / \mathrm{cm}^{2}$ loading concentration. Grazing angle spectra of samples were collected for surface concentrations in the range of $0.1-20 \mu \mathrm{g} / \mathrm{cm}^{2}$ FT-IR spectra were collected from each plate using the grazing angle probe. The spectra are shown in Figure 3. Fingerprint signals intensities of the spectra decrease with lower ibuprofen loading concentrations. This amplified region was used for the chemometrics calculations (Beebe, 1998). The most intense band of ibuprofen in the region of $1760-1650 \mathrm{~cm}^{-1}$ was used for peak area and peak height calibration curve generation. This band is assigned to $\mathrm{C}=\mathrm{O}$ stretch (Griffith, 1986; Lin-Vien, 1991). 


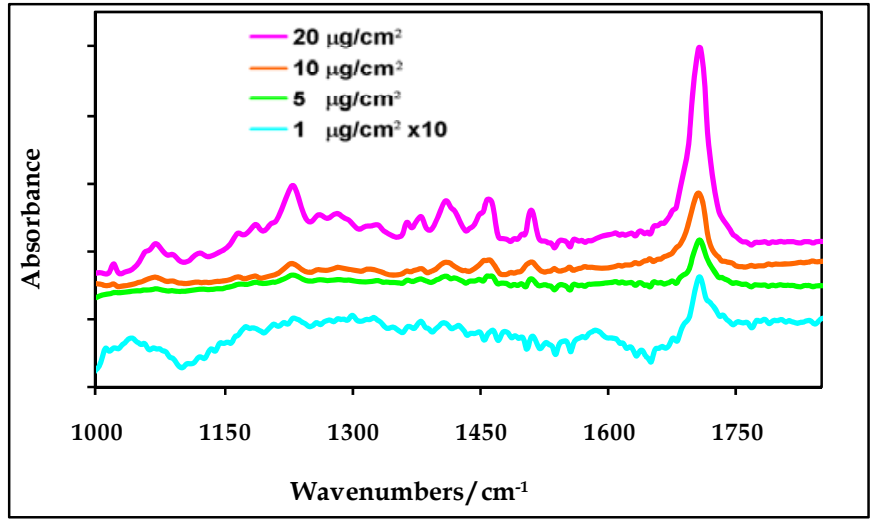

Fig. 3. Grazing angle FTIR spectra of ibuprofen on stainless steel for various surface loadings For quantification studies, two types of calibration curves were generated using two methods: measurement of the absorbance peak heights and integration of areas spectral region within the 1760 to $1650 \mathrm{~cm}^{-1}$ range. Fig. 3 shows the calibration curves of the absorbance peak heights. Results for peak areas are not shown. These plots exhibit a high degree of linear correlation. The calibration curve graph using height peaks shows better in linearity. However, the errors are higher for the calibration curve using peak areas. The calibration graphs using peak areas represents a better choice for quantitative analysis when compared to peak height analysis (Lavine, 2002; Kramer, 1998).

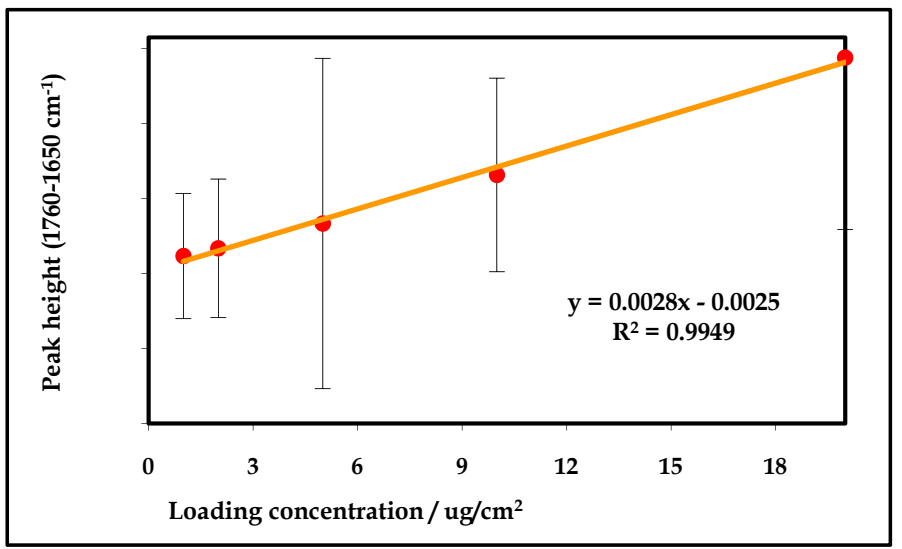

Fig. 4. Calibration curve of ibuprofen using peak height analysis

The calibration model was built using the Quant 2 package, an add-on software package to the OPUS ${ }^{\mathrm{TM}}$ (Bruker Optics) data acquisition and analysis software. In this study, the model parameters were optimized in the spectral region $1770-1016 \mathrm{~cm}^{-1}$ and $3104-2750 \mathrm{~cm}^{-1}$. No spectral data preprocessing was done. The resulting model was cross-validated using the "leave one out" method in which each spectrum is omitted in turn from the training set and then tested against the model built with the remaining spectra. The results are illustrated 
graphically in Fig. 5. The root mean square error of the cross validation was 0.401 , and $\mathrm{R}^{2}$ was 0.9952. Clearly, low levels of ibuprofen can be detected and measured on a metal surface with quantitative results.

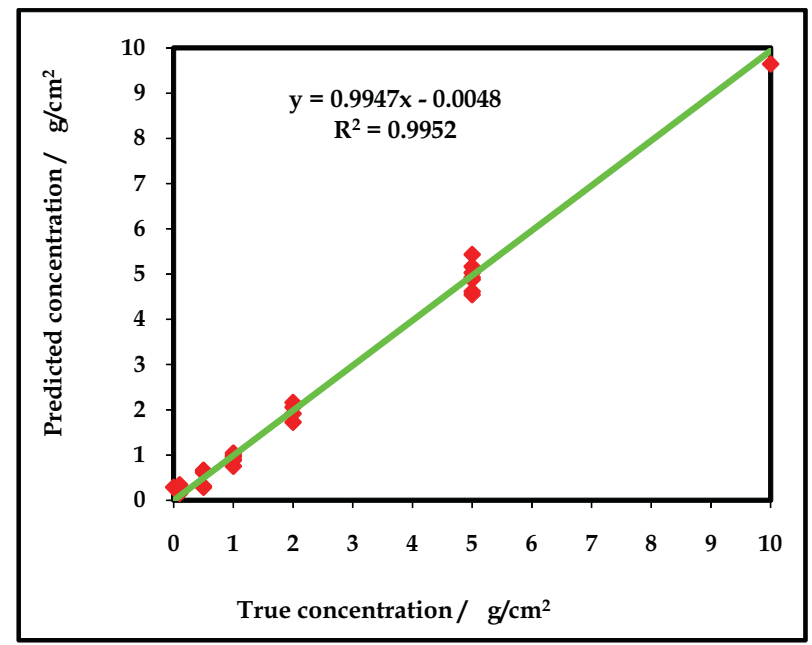

Fig. 5. Cross validation for Ibuprofen quantification on metallic surfaces

Discriminant analysis (Huberty, 1994) was also performed to classify ibuprofen loading concentration in two groups (Fig. 6). The first one corresponds to concentrations $<2 \mu \mathrm{g} / \mathrm{cm}^{2}$ and the second one to concentrations $>2 \mu \mathrm{g} / \mathrm{cm}^{2}$. Peak areas of signals in the range of $1273-$ $1978 \mathrm{~cm}^{-1}$ were used for the discrimination. This model was generated using 10 PLS and submitting the data to a pre-processing of straight line subtraction. Results show that discriminant analysis can be used to classify ibuprofen samples according to their surface concentration on the metal surfaces. The minimum amount of this API on the reactor after cleaning must be considered for future works. This will allow having a real model of discrimination.

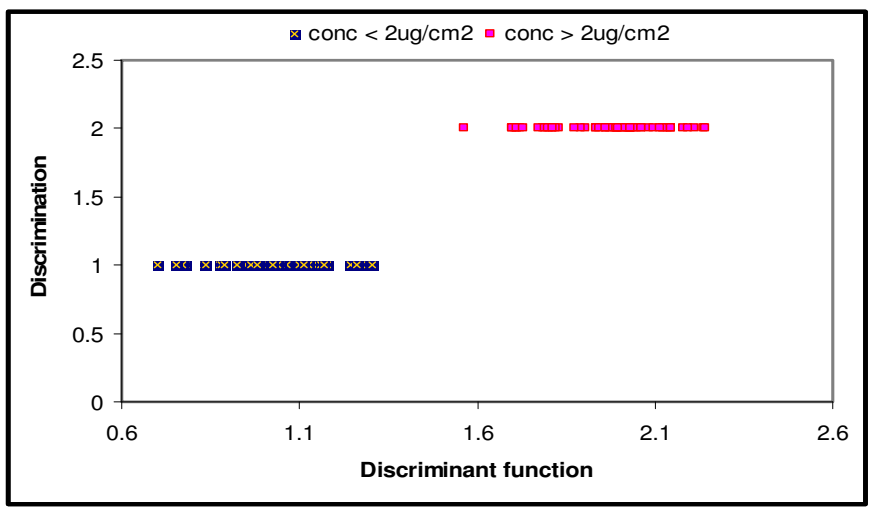

Fig. 6. Discrimination study for ibuprofen: samples were separated according to surface loadings 


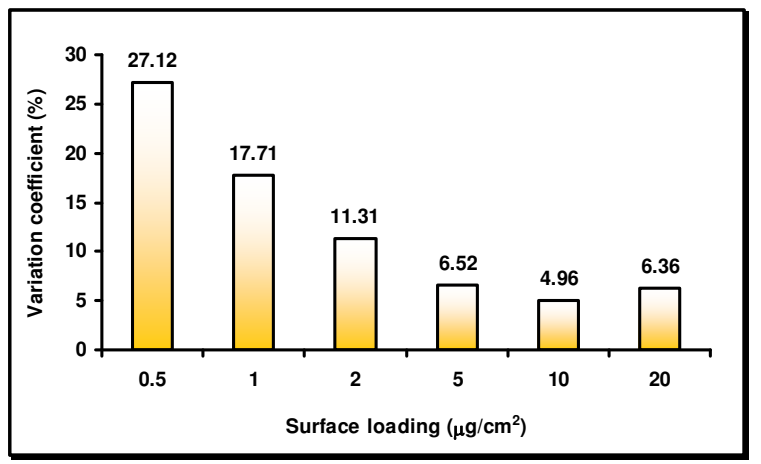

Fig. 7. Variation coefficient with surface loadings for detection and quantification limit calculations

The variation coefficient (Fig. 7) increases at low surface loadings. For $0.5 \mu \mathrm{g} / \mathrm{cm}^{2}$ loading concentration, the variation was higher than the others. This indicates that at this surface loading, the analytical response gets its minimum value and can be confused with the noise. This value can be considered as the detection limit. In order to verify this, an ANOVA test was performed for surface concentrations of $0.5,1 \mathrm{y} 2 \mu \mathrm{g} / \mathrm{cm}^{2}$, and for a $95.0 \%$ confidence level there was a statistically significant difference between these values. However at $99.0 \%$ confidence level, there was no difference for samples of 0.5 and $1 \mu \mathrm{g} / \mathrm{cm}^{2}$ (Statgraphics Plus for Windows ${ }^{\mathrm{TM}}$, 1999).

\section{Detection of explosives}

FOC-GAP-FTIR spectroscopy is suitable for development of methods for detection of traces of explosives on surfaces. A smearing transfer method can be used for depositing the target explosives on the substrates to be used as standards and samples. The sample transfer method is appropriate to compare with other methods of sample preparation due the fact that a mass balance is not needed in order to know the amount of the sample on the surface. Besides that, many plates were prepared, good reproducible distributions were found (the analyte was distributed almost homogeneous on the surface). Samples ranging from micrograms $/ \mathrm{cm}^{2}$ to nanograms $/ \mathrm{cm}^{2}$ of 2,6-dinitrotuelene (DNT), 2,4,6-trinitrotoluene (TNT), pentaerythritol tetranitrate (PETN), nitroglycerine (NG) and triacetone triperoxide (TATP) were deposited as on stainless steel surface. Methanol, acetone and acetonitrile were used as transfer solvents. The IR reflectance spectra were recorded at $4 \mathrm{~cm}^{-1}$ resolution and 50 scans. The results of the experiments gave intense absorption bands in the fingerprint region of the IR spectra that were used to calculate the detection limit for each of the target explosives. The nitro band can be used for explosives detection since it acts as a vibrational signature of several classes of explosives: nitroaromatic, nitroaliphatic, nitramines and nitrate esters. Figs. 8 and 9 show the prominent signal of nitro explosives deposited on stainless steel surfaces. Only one signal in the range $1200-1400 \mathrm{~cm}^{-1}$ was significant for quantitative and qualitative analysis. This band can be attributed $\mathrm{NO}_{2}$ stretching vibration. Nitro stretching vibration of PETN and NG appears in the $1250-1320 \mathrm{~cm}^{-1}$ region. For nitroaromatic explosives such as TNT and 2,6-DNT the band appears at $1320-1360 \mathrm{~cm}^{-1}[42$, 43]. 
This difference can be explained in terms of the fact that the group $\mathrm{NO}_{2}$ in PETN and NG is attached to an oxygen atom. However, in DNT and TNT, this nitro group is directly attached to the aromatic ring. The high electronegativity of the oxygen atom in PETN and NG attracts electron density from the nitro group leading to a lowering of the oscillator strength and causing a shift to lower frequencies. This effect is lower or not present in the aromatic ring for TNT and DNT.
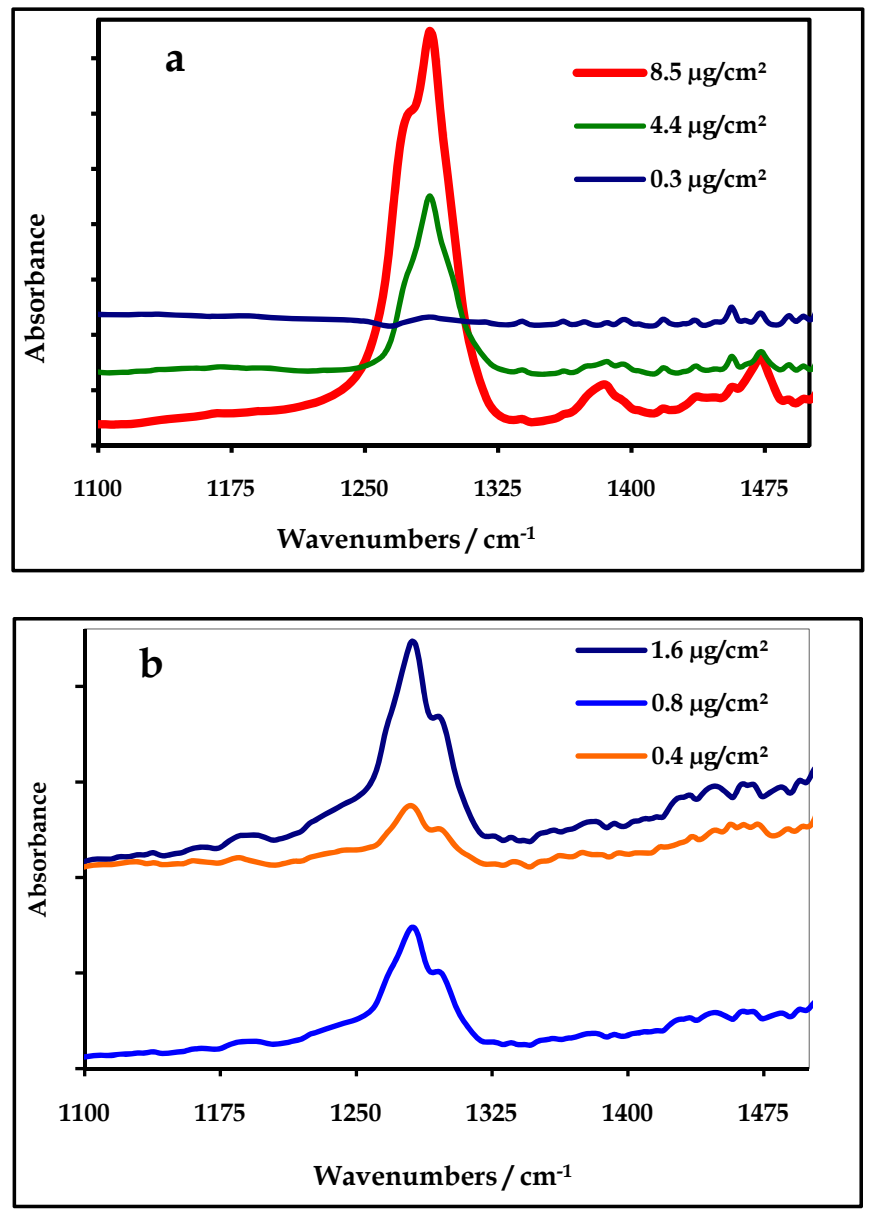

Fig. 8. Grazing angle spectra of nitroexplosives: a. PETN; b. NG

Fig. 10 includes the calculated classical detection limits for some nitroexplosives. For surface loadings near the detection limit only the $\mathrm{NO}_{2}$ signal can be observed without aid of software. The detection limit varies according to macro properties. Properties such vapor pressure, physical adsorption, sublimation rate and surface-adsorbate thermodynamics can influence the detection limit. A close relation between vapor pressure and limit detection is shown for nitro explosives. Table 1 shows the values for the vapor pressures near room temperature of the explosives studied. The amount of explosive on surface of stainless steel 
and the residence time depends on this property, because at this loading concentration the explosive goes to vapor phase fast. This phenomenon is remarkably observed in TATP with detection limit of $8 \mu \mathrm{g} / \mathrm{cm}^{2}$. Some macro properties also can affect sublimation at room temperature and TATP detection limit.

Fig. 11 illustrates that several TATP bands can be used for its detection with accuracy. It shows the prominent presence of the most intense bands of TATP in the IR fingerprint region. The band at $1205 \mathrm{~cm}^{-1}$ belongs to the $\mathrm{C}-\mathrm{O}$ stretch, $1365 \mathrm{~cm}^{-1}$ is a deformation of $\mathrm{CH}_{3}$ group and the band at $1471 \mathrm{~cm}^{-1}$ is an asymmetric deformation of $\mathrm{CH}_{3}$ group. The spectroscopic window used for TATP detection was spectral range of 1320-1407 $\mathrm{cm}^{-1}$. Forward selection analysis of variable significance affirms that the significant peaks were contained within the spectral range of 1330-1407 $\mathrm{cm}^{-1}$ (Beeson, 1998; Demuth, 1998). The best discriminant model was done using peak areas. It was selected based on statistical significance and the percent of cases correctly classified. The statistical significance value ( $\mathrm{p}$ value) was $p<0.0001$ and the percent of cases correctly classified was $90.6 \%$.
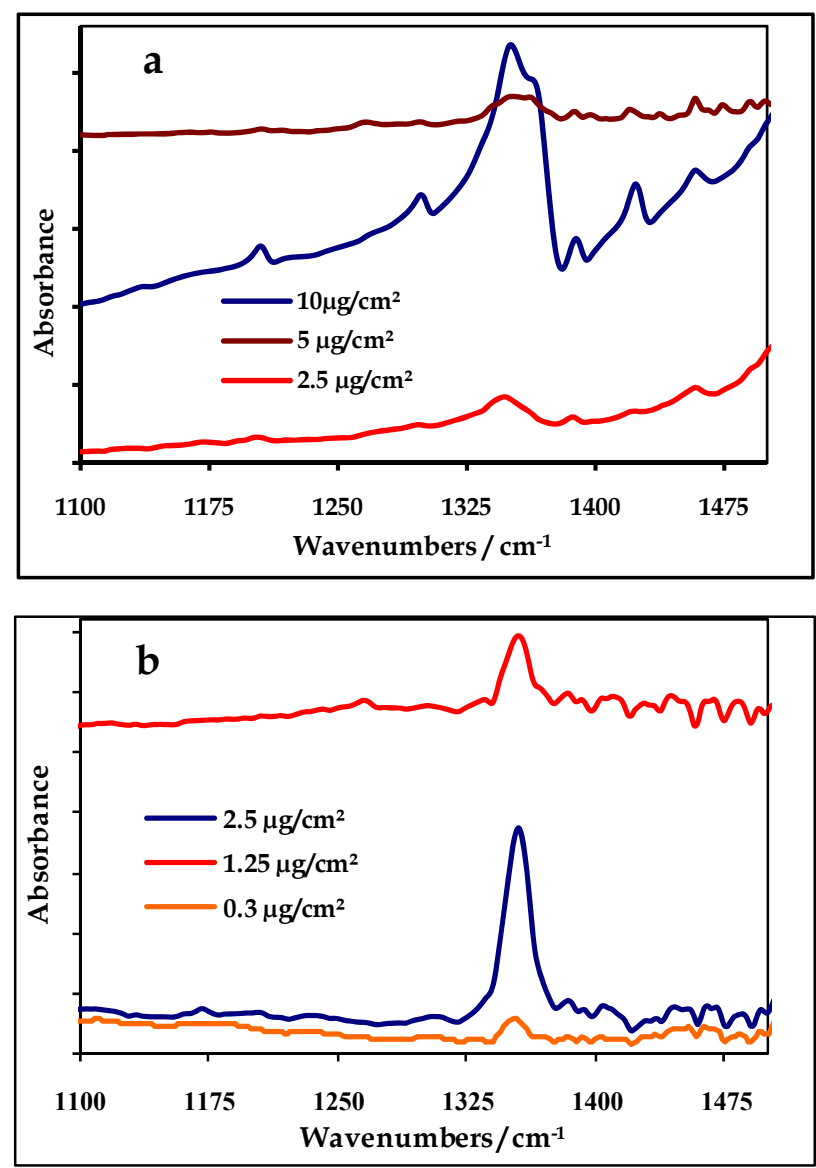

Fig. 9. Grazing angle spectra of nitroexplosives: a. 2,6-DNT; b. TNT 


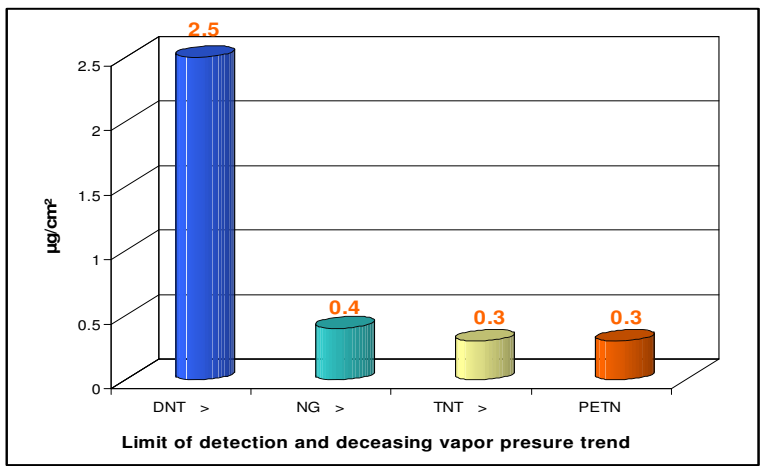

Fig. 10. Detection limits for selected nitroexplosives and correlation with decreasing vapor pressure of the energetic compound

\begin{tabular}{cc}
\hline \hline Explosive & Vapor pressure $(\mathbf{m m ~ H g})$ \\
\hline 2,6-dinitrotoluene & $5.67 \times 10^{-4}$ at $25^{\circ} \mathrm{C}$ \\
2,4,6-trinitrotoluene & $1.99 \times 10^{-4}$ at $20^{\circ} \mathrm{C}$ \\
nitroglycerin & $2.0 \times 10^{-4}$ at $25^{\circ} \mathrm{C}$ \\
pentaerythritol tetranitrate & $1.035 \times 10^{-10}$ at $25^{\circ} \mathrm{C}$ \\
TATP & $5.25 \times 10^{-2}$ at $25^{\circ} \mathrm{C}$ \\
\hline \hline
\end{tabular}

Table 1. Vapor pressure of nitroexplosives and TATP

It is important to emphasize that measuring surface concentrations using the peak area method is conceptually simple and easy to use, but it has limitations. The method is univariate (the concentration is determined with a single spectral peak) and depends on a linear correlation between the concentration and the spectral response. The results can, therefore, be undermined by perturbations such as fluctuations caused by detector noise, temperature variations, or molecular interactions. Statistically based, multivariate calibrations use spectral features over a wide range. Information from a calibration spectral set (a training set) was compared to independently determined concentration data using partial least squares (PLS) regression. This method is based on the assumption that systematic variations in the spectra are a consequence of concentration changes. A calibration model for analysis of 2,6-DNT was built using the Quant 2 package, an add-on software package to the OPUSTM data acquisition and analysis software (Bruker Optics). The best spectral region was in the range of $1702-1269 \mathrm{~cm}^{-1}$. This range was used for model generation. No spectral data preprocessing was applied to the spectra. The results are illustrated graphically in Fig. 12. The root mean square error of the cross validation (RMSCV) was 0.957 , and \% $\mathrm{R}^{2}$ was 97.75 . This calibration was used in order to predict unknown loading concentrations. For a deposited loading concentration 3.78 and 7.56 $\mu \mathrm{g} / \mathrm{cm}^{2}, 3.58$ and $7.35 \mu \mathrm{g} / \mathrm{cm}^{2}$ were detected, respectively. Clearly, low levels of explosives can be detected and measured on a metal surface with good results. So, chemometrics easily leads to a powerful technique for surface contamination detection and measurement. Moreover, classical detection limits do not apply any longer. Thus the reported values are on the conservative side. 


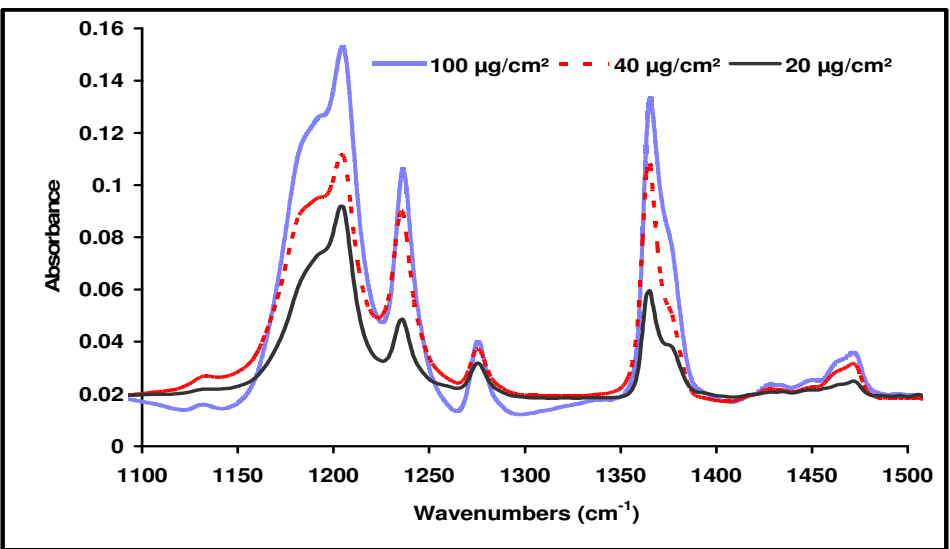

Fig. 11. GAP spectra of TATP at three surface loadings: 20, 40 and $100 \mu \mathrm{g} / \mathrm{cm}^{2}$

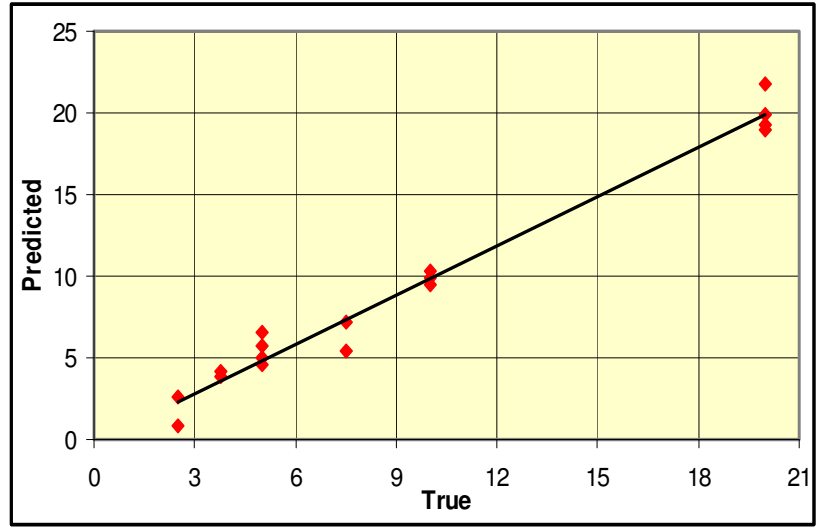

Fig. 12. Partial least squares regression cross validation plot for 2,6-DNT

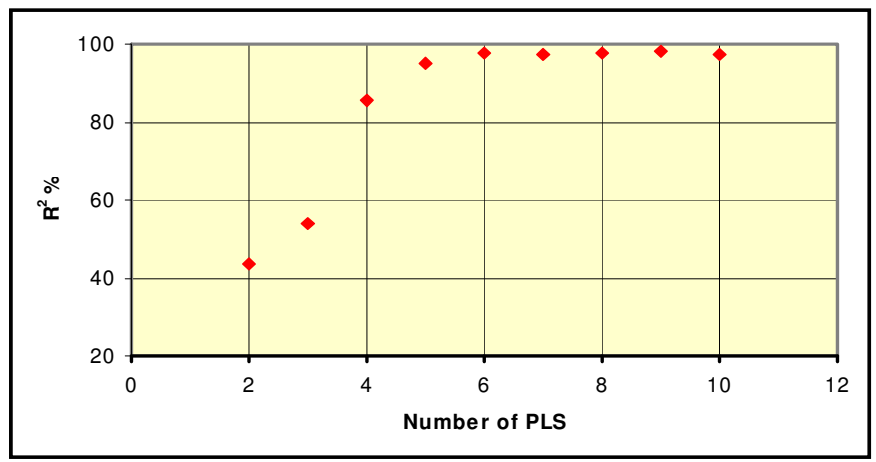

Fig. 13. Variation of $\% \mathrm{R}^{2}$ with the number of PLS carried out 
The importance of applying PLS that it is used to design and build robust calibration models for quantitative analysis. PLS regression is a quantitative spectral decomposition technique that is closely related to principal component (PC) regression. It uses the concentration information during the decomposition process. This causes spectra containing higher constituent concentrations to be weighted more heavily than those with low concentrations. The main idea of PLS is to get as much concentration information as possible into the first few loading vectors or number of PLS (Kramer, 1998; Otto, 1999).

Fig. 13 shows how the calibration model improves with the addition of PLS. Five PLS executions were necessary to build a good calibration model. This indicates that the relationship that exists between the loading concentration and the spectral absorbance in this technique is multidimensional. The robustness of model calibration was evaluated using internal jackknifing validation [44]. Model with lower PLS than 6 was not capable to predict new data with good precision. Fig. 14 shows the appearance of TNT deposits under high magnification of a white light microscope. At these loading concentrations almost all the stainless steel surface was covered by crystals. Using this transfer method, positive and inverted bands were observed (Fig. 15). For loading concentrations $>8 \mu \mathrm{g} / \mathrm{cm}^{2}$, only positive bands were observed. This fact can be attributed some changes in the refraction index of TNT.

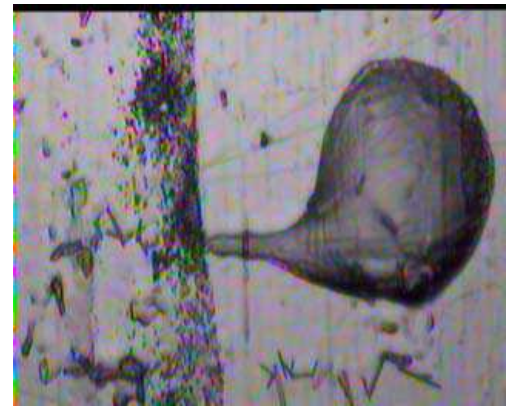

a. $20 \mu \mathrm{g} / \mathrm{cm}^{2} 50 \mathrm{x}$

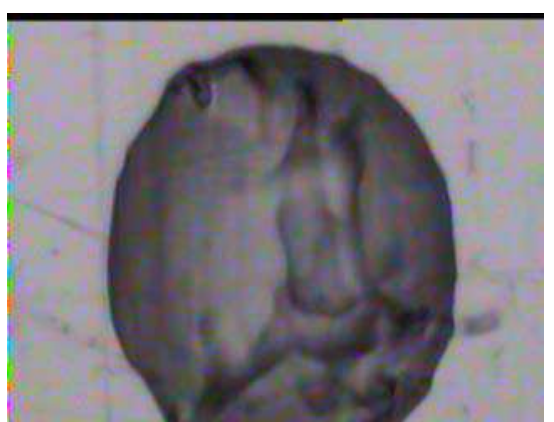

b. $40 \mu \mathrm{g} / \mathrm{cm}^{2} 100 \mathrm{x}$

Fig. 14. Optical images for TNT deposited on stainless steel using smearing method

\begin{tabular}{ccccc}
\hline \hline Substance & $\begin{array}{c}\text { Sample } \\
\text { Preparation Method }\end{array}$ & Solvent & $\begin{array}{c}\text { Detection Limit } \\
\left(\mathbf{\mu g} / \mathbf{c m}^{2}\right)\end{array}$ \\
\cline { 3 - 5 } TNT & Smearing & dichloromethane & 0.3 \\
2,6-DNT & Smearing & acetone & 0.3 \\
PETN & Smearing & methanol & 0.3 \\
NG & Smearing & acetonitrile & 0.4 \\
TATP & Smearing & dichloromethane & 8.0 \\
\hline \hline
\end{tabular}

Table 2. Detection limits of Explosives using FT-RAIRS on stainless steel

The calibration model was built using the Quant 2 package, an add-on software package to the OPUSTM (Bruker Optics) data acquisition and analysis software. In this study, the model parameters were optimized in the spectral region 1668-1045 $\mathrm{cm}^{-1}$. No spectral data preprocessing was done. The resulting model was cross-validated using the "leave one out" 
method in which each spectrum is omitted in turn from the training set and then tested against the model built with the remaining spectra. The results are illustrated graphically in Fig. 16. The root mean square error of the cross validation was 0.918 , and $R^{2}$ was 0.9858 . TNT can be detected and quantified on metallic surfaces and low concentrations as 500 $\mathrm{ng} / \mathrm{cm}^{2}$. Table 2 shows a summary of the detection limits of the explosives using smearing transfer method. The detection limit depends on the vapor pressure.

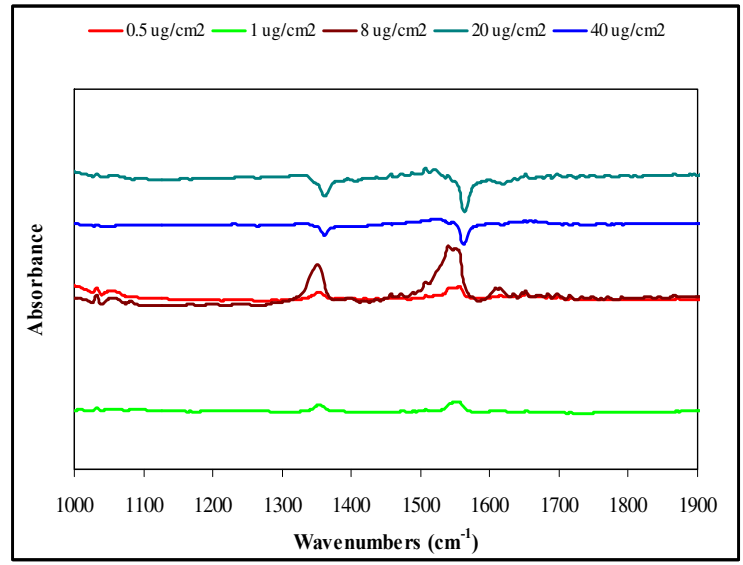

Fig. 15. FT absorption-reflection IR spectra of TNT on stainless steel using smearing transfer method

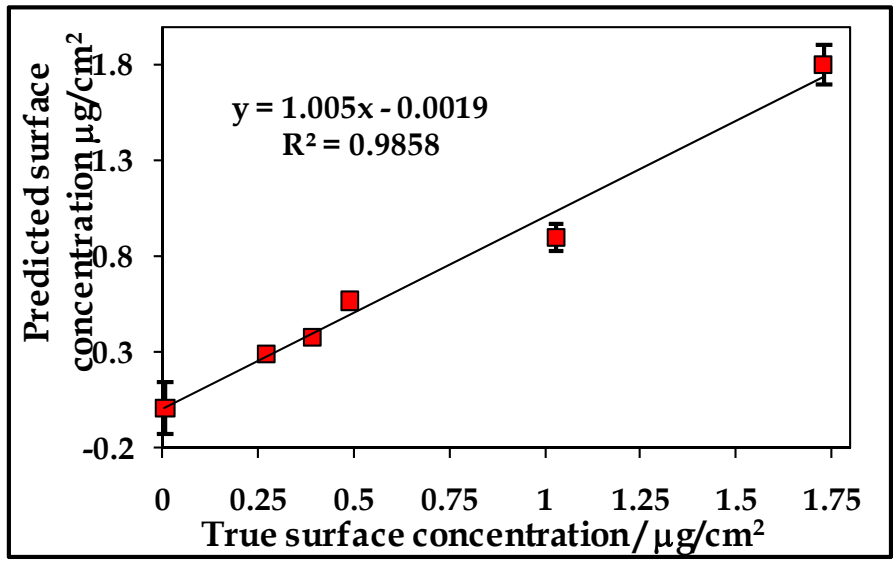

Fig. 16. Leave one out cross validation for TNT surface concentration deposited on stainless steel

\section{Sublimation studies of TATP deposited on metal surfaces}

The rapid sublimation of the TATP under normal atmospheric conditions presents a significant challenge in applying the fiber-optic grazing-angle method to surface detection 
of the compound. Even under controlled laboratory conditions, where spectroscopy was carried out on freshly prepared samples, it proved impossible to develop PLS1 calibrations that met a high standard of robustness or usability. The rapid change in the surface concentration of TATP made it impractical to collect more than one spectrum from each sample and this further limited the possibilities of building a statistically useful data set. The samples were deposited on the surface using a smearing method. To carry out the experiments, TATP was synthesized in the laboratory. For the calibration curves TATP was dissolved in dichloromethane. A solution with an initial concentration of $0.23 \mathrm{~g} / \mathrm{mL}$ was prepared and then dilutions were made until obtain $0.23 \mathrm{~g} / \mathrm{mL}$. The resulting average surface concentrations of TATP ranged from 8 to $200 \mu \mathrm{g} / \mathrm{cm}^{2}$. Since dichloromethane evaporates very fast (Boiling point $=39.8^{\circ} \mathrm{C}$ ), a thin sample film was observed after smearing. Once the solvent had evaporated, the spectrum of the sample was collected immediately to minimize the impact on the calibration of rapid TATP sublimation. The data was analyzed using chemometrics routines; in particular multivariate PLS was used. In other experiments done with stainless steel plates coated with $25-100 \mu \mathrm{g} / \mathrm{cm}^{2} \mathrm{TATP}$, spectra were recorded every 27 seconds at $20-30{ }^{\circ} \mathrm{C}$ and the sublimation behavior at the studied temperatures was observed.

The readiness with which TATP sublimates (vapor pressure at room temperature $=7 \mathrm{~Pa}$ ) under normal atmospheric conditions complicates the task of calibrating the detection of the compound on surfaces, as the surface concentration of TATP decreases over the timescale of the experiment. To explore this effect, experiments were performed with stainless steel plates initially given a nominal loading of $100,80,50,20$, and $10 \mu \mathrm{g} / \mathrm{cm}^{2}$ TATP. Immediately after deposition of the TATP, the probe head was positioned on the surface, and spectra were collected every 27 seconds. Fig. 17 shows successive spectra taken at $27 \mathrm{~s}$ intervals from an initial loading of $100 \mu \mathrm{g} / \mathrm{cm}^{2}$ TATP.

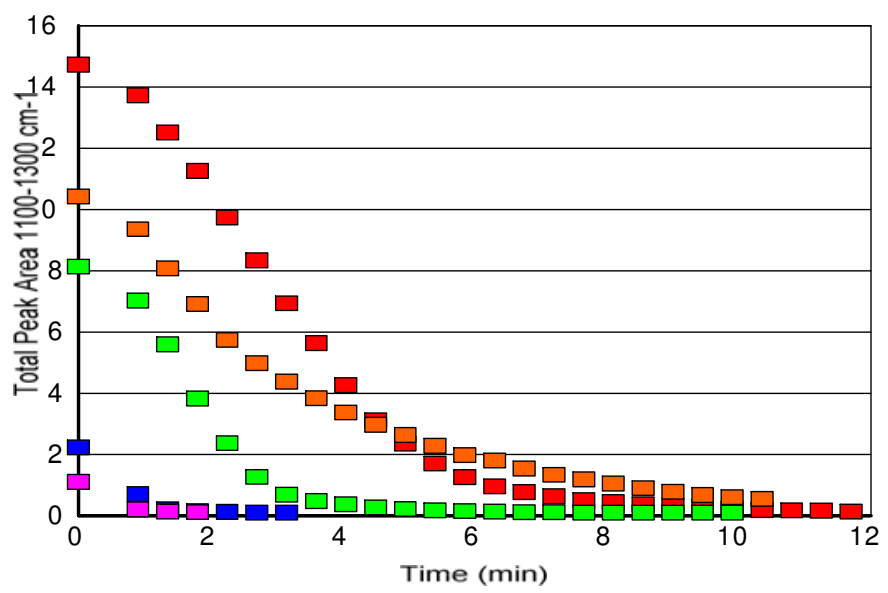

Fig. 17. Peak areas for the grazing-angle mid-IR spectra in the range from $100-1300 \mathrm{~cm}^{-1}$, for initial loadings of $100,80,50,20$, and $10 \mu \mathrm{g} / \mathrm{cm}^{2}$

A peak-fitting model of the spectral region from approximately $1300-1100 \mathrm{~cm}^{-1}$ was fitted against each of the spectra in turn to give the total peak area for the selected region. Fig. 18 
shows the result for samples of stainless steel substrates initially loaded with $10-100 \mu \mathrm{g} / \mathrm{cm}^{2}$, represented as a graph of peak areas versus time. The amount of TATP detected on the surface drops below the apparent detection limit of the technique within about $9 \mathrm{~min}$.

Standard were prepared as described in the Experimental Section. Grazing angle FT-IR spectra of freshly prepared samples were collected for a series of different surface concentrations, as shown in Table 1. When a PLS1 model was built from all of the 79 spectra listed, using the spectral region from 1066-1506 $\mathrm{cm}^{-1}$ and no spectral preprocessing, it proved impossible to develop a model that met a reasonable standard (the maximum obtainable value for $\mathrm{R}^{2}$ was about 0.75 ). In this study, the model parameters were optimized in the spectral region $1498-1113 \mathrm{~cm}^{-1}$. No spectral data preprocessing was done. When data used for the model was limited to loadings below $40 \mu \mathrm{g} / \mathrm{cm}^{2}$, it was possible to build a calibration with $\mathrm{R}^{2}=0.869$, and root mean square error of cross validation (RMSECV) $=3.69$ (obtained from a leave-one-out cross validation); the results are shown graphically in Fig. 18. The graph shows the degree of scattering in the data. While some of this scattering may be attributable to variations in the amount of TATP deposited on each coupon, sublimation of the TATP during the experiment is another likely contributing factor. Given these limitations, the quality of the calibration that has been developed is surprisingly good and it is clearly quite possible to detect microgram quantities of TATP on metal surfaces using grazing angle FTIR methods. This is in agreement with previous results for a range of organic compounds on metal and glass surfaces (White, 1992; Lin-Vien, 1991).

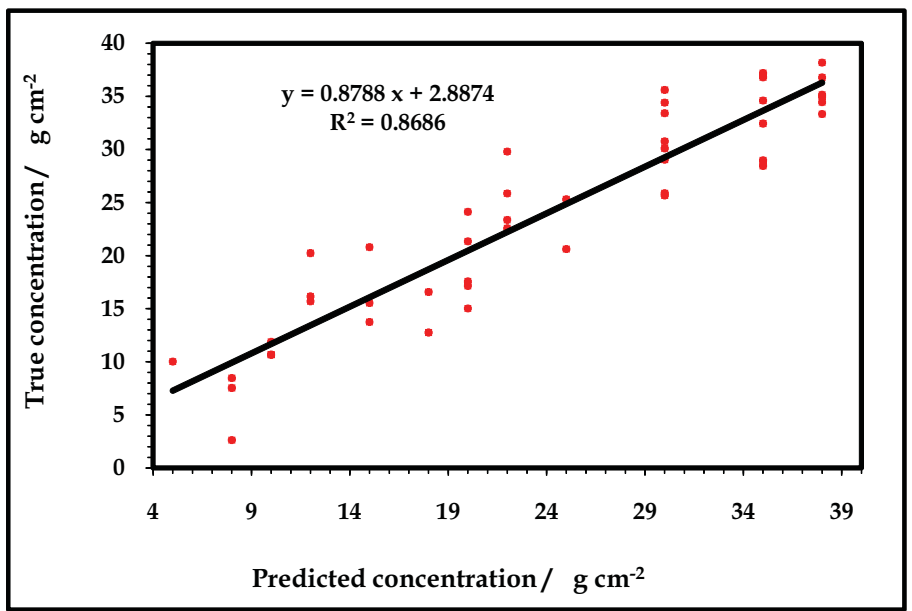

Fig. 18. "Leave-one-out cross" validation of predicted values vs. true values for TATP on stainless steel substrates. All data are shown illustrating point scattering at each value measured

TATP quantification was done using the calibration generated by chemometrics. These results are shown in Table 3. Clearly, low levels of TATP can be detected and measured on a metal surface with quantitative results (Table 4). Attempts to build a separate calibration for the loadings of $40 \mu \mathrm{g} / \mathrm{cm}^{2}$ and above were unsuccessful may be attributable to the change in the nature of the surface coating at high loadings, from a thin film capable of generating a double-pass transmission spectrum to a bulk material generating diffuse surface reflectance 
independent of the thickness (Blaudez, 1998; Bradshaw, 1988; Hayden, 1987). Calibration curve is shown in Fig. 19.

A true "transflectance" experiment is possible only when the layer of organic material is "very" thin, so that the IR radiation can pass all the way through it to be reflected from the substrate (e.g. the metal). If the coating is thicker than about 1 or 2 micrometers, the IR radiation does not reach the substrate and is reflected from the top surface of the organic material (as if it were a "bulk" sample of the organic material) to give diffuse reflectance (Kaihara, 2001). This changes the spectrum that is obtained from the organic material from the "transflectance" spectrum to a diffuse reflectance spectrum. The diffuse reflectance spectrum is not affected by the thickness of the coating, since it does not come from the whole coating but only from the top layer, and so it does not contribute to a useful calibration.

\begin{tabular}{|c|c|c|}
\hline TATP Loading $\left(\mu \mathrm{g} / \mathrm{cm}^{2}\right)$ & Number of Spectra & Included in Calibration \\
\hline 5 & 1 & No \\
\hline 8 & 3 & Yes \\
\hline 10 & 4 & Yes \\
\hline 12 & 4 & Yes \\
\hline 15 & 4 & Yes \\
\hline 18 & 3 & Yes \\
\hline 20 & 7 & Yes \\
\hline 22 & 5 & Yes \\
\hline 25 & 3 & Yes \\
\hline 30 & 9 & Yes \\
\hline 35 & 7 & Yes \\
\hline 38 & 7 & Yes \\
\hline 40 & 8 & No \\
\hline 50 & 2 & No \\
\hline 60 & 2 & No \\
\hline 80 & 2 & No \\
\hline 90 & 2 & No \\
\hline 150 & 1 & No \\
\hline 200 & 1 & No \\
\hline
\end{tabular}

Table 3. List of TATP spectra collected for calibration 


\begin{tabular}{|c|c|c|}
\hline $\begin{array}{l}\text { Deposited } \\
\left(\mu \mathrm{g} / \mathrm{cm}^{2}\right)\end{array}$ & $\begin{array}{l}\text { Detected by grazing angle } \\
\qquad\left(\mu \mathrm{g} / \mathrm{cm}^{2}\right)\end{array}$ & Difference \\
\hline 14.96 & 13.8 & 1.16 \\
\hline 17.96 & 16.5 & 1.46 \\
\hline 24.94 & 25.3 & -0.36 \\
\hline 34.91 & 32.6 & 2.36 \\
\hline
\end{tabular}

Table 4. Quantification of TATP on metal plates by grazing angle Fiber optic FT-IR

Discriminant analysis was also performed to classify the TATP loading concentration in two groups (Fig. 20). The first one corresponds to concentrations lower than $25 \mu \mathrm{g} / \mathrm{cm}^{2}$ and the second one to concentrations higher than $25 \mu \mathrm{g} / \mathrm{cm}^{2}$. Peak areas of signals in the range of 1330-1407 $\mathrm{cm}^{-1}$ and 1407-1503 $\mathrm{cm}^{-1}$ were used for the discrimination. Forward selection analysis of variable significance affirms that the significant peaks were contained within the spectral range of 1330-1407 $\mathrm{cm}^{-1}$. The best discriminant model was selected based on statistical significance and the percentage of cases correctly classified. The percentage of cases correctly classified was $90.6 \%$ and the significance statistical p-value was $<0.0001$.

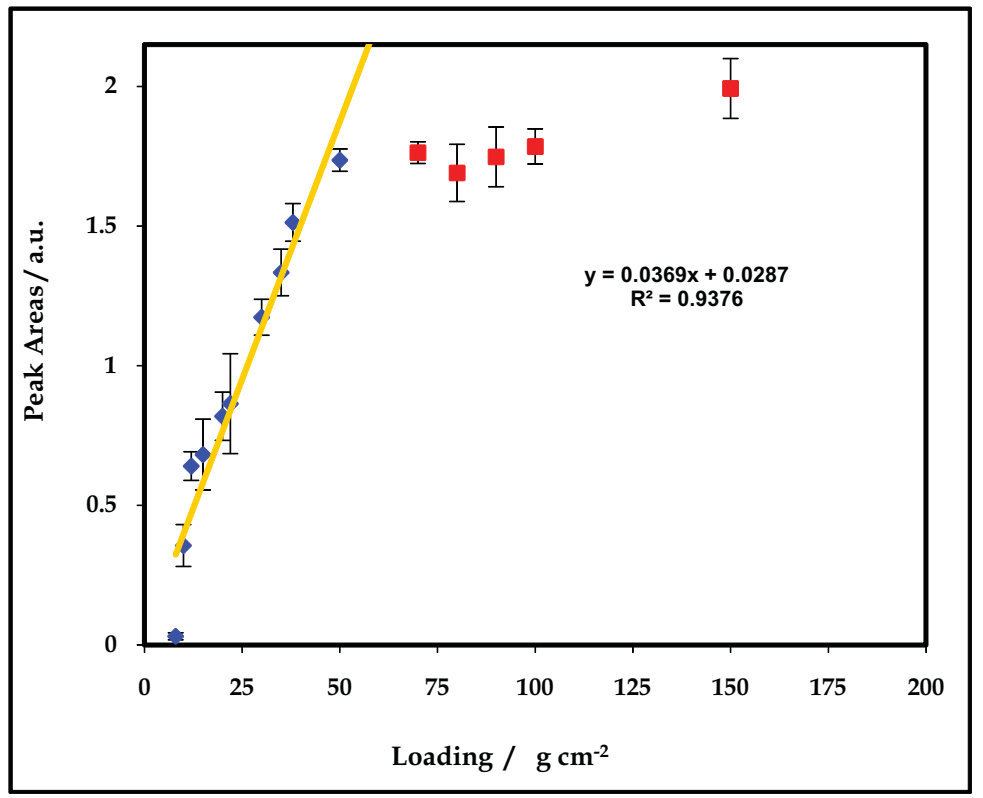

Fig. 19. Calibration curve for TATP on SS surface using peak areas $\left(1330-1407 \mathrm{~cm}^{-1}\right)$

TATP sublimation behavior depends of the temperature as is expected. This is shown in Fig. 21. For temperatures lower than $20^{\circ} \mathrm{C}$ TATP sublimation rate is significantly low. Beyond this point the sublimation rate starts to increase very fast. The rate of sublimation for TATP was calculated in units of peak-area/second for the slope of the curve, taking into account the linear range of the graphs (Fig. 21-a and -b). Since the surface concentration is well approximated by the measured peak area in this range because these are proportional (Fig. , the mass transferred to the vapor phase is reasonably well estimated by the decrease in peak 
areas in the MIR. This range was selected because here the rate decays more rapidly. These results can be confirmed in Fig. 19. The estimated value of the rate sublimation with temperature in the range of $20-30{ }^{\circ} \mathrm{C}$ is -0.0013 peak area- $\mathrm{s}^{-1}{ }^{\circ} \mathrm{C}^{-1}$. This is equivalent to $\sim-0.81$ $\mu \mathrm{g} \mathrm{cm}^{-2} \mathrm{~s}^{-1}{ }^{\circ} \mathrm{C}^{-1}$ in the range of $20-30{ }^{\circ} \mathrm{C}$. These experiments confirm the fact that TATP sublimates very fast in the absence of vapor pressure reducing and stabilizing agents.

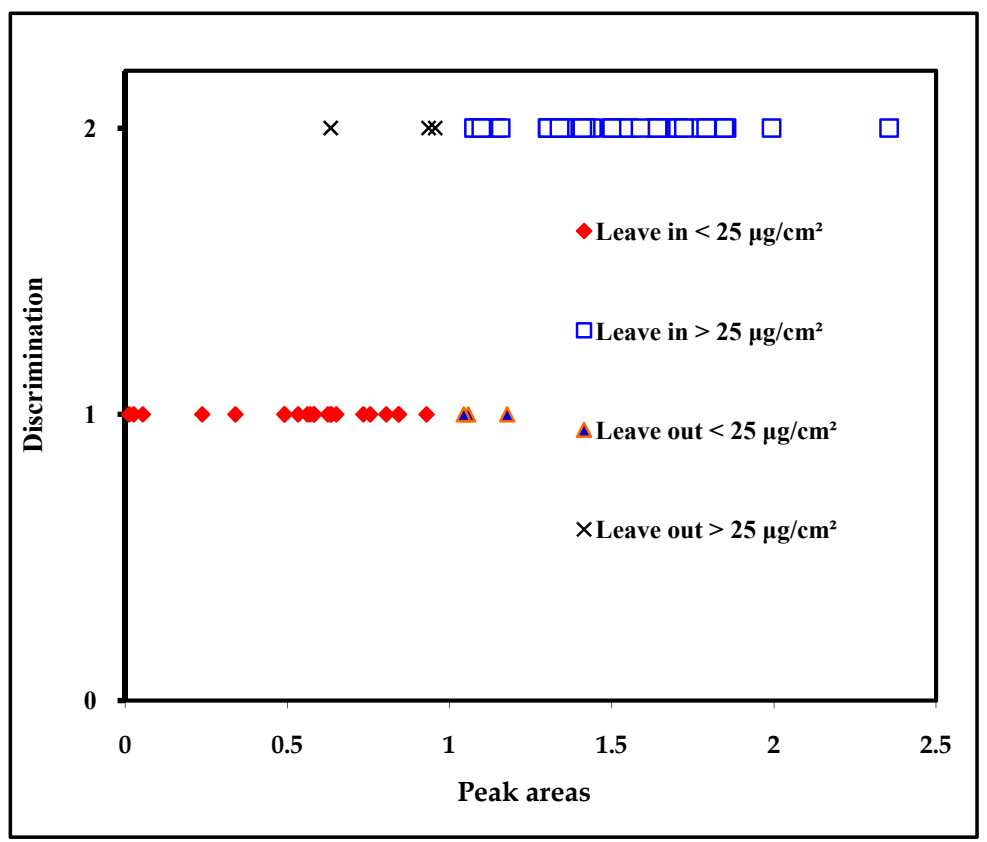

Fig. 20. Plot of peak area selected to construct the discrimination for grouping 67 concentrations
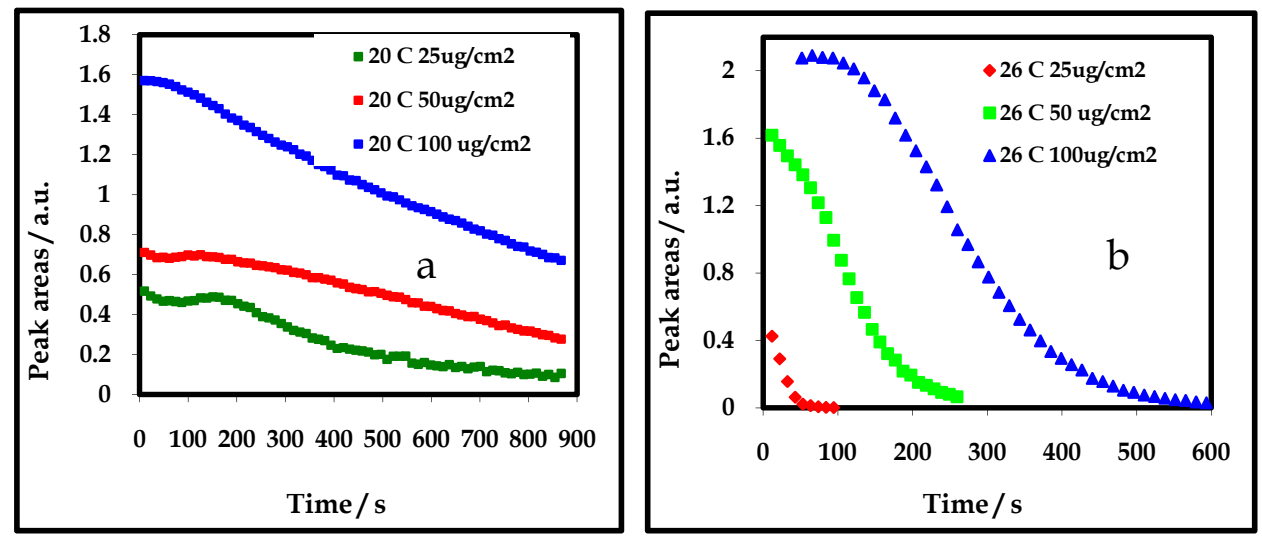

Fig. 21. Plots of peak areas versus time (second) for 25,50 and $100 \mu \mathrm{g} / \mathrm{cm}^{2}$ at: a: $20^{\circ} \mathrm{C} ; \mathrm{b}: 26^{\circ} \mathrm{C}$ 

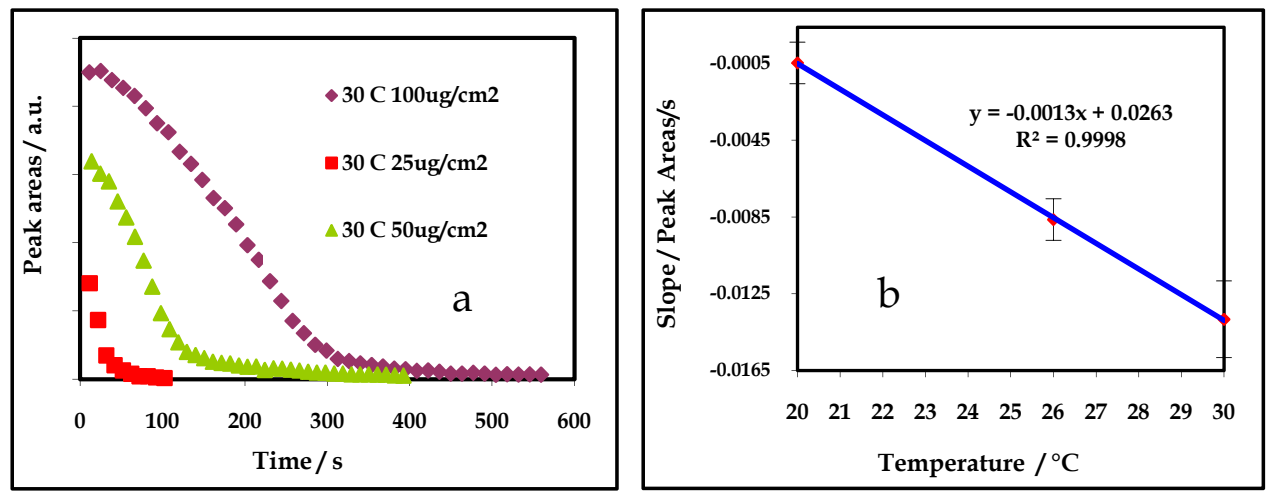

Fig. 22. a: Plot of peak areas versus time (s) for 25,50 and $100 \mu \mathrm{g} / \mathrm{cm}^{2}$ at $30^{\circ} \mathrm{C}$; b: sublimation rate for different temperatures

\section{Characterization studies of TNT deposited on metal surfaces by TIJ technology}

Although smearing transfer method gave almost a homogenous distribution of the explosives on surfaces, the method of mass transfer required the preparation of many samples. This was due to the fact that the sample transfer method is prone to uncontrolled operator errors. To circumvent the problem, Thermal inkjet technology (TIJ) was used for the experiments. TNT was selected as an explosive for dispensing on TIJ.

Thermal Inkjet Technology is able to deposit very small amounts of chemical compounds, including energetic materials, in a specific location on a surface. Aliquots of TNT solutions were deposited on stainless steel film. A coating of TNT can be produced by controlling the concentration of TNT, the number of drops dispensed and the distribution of drops over the surface. The loading concentration of the sample on the surface can be controlled by varying parameters such as: number of passes, dispensing frequency, applied energy and pen architecture. Precise delivery of known number of droplets with known mass and concentration are known. Also only one solution can be used, avoiding dilutions that can increase the analytical errors.

The precise amount of TNT on the surface can be known in different ways: one can be known if the drop weight of the solutions is known and the other using an alternative method for quantification (GC, UV or HPLC). In our study, the stainless steel sheets loaded with TNT samples were rinsed with $25-100 \mathrm{~mL}$ of acetonitrile to remove the entire TNT that was delivered on the surface. Then solutions were transferred a volumetric flask and filled to mark with solvent. Gas chromatography was used in our experiments as an alternative method in order to determine the surface loading concentration. The analysis was carried out using an Agilent Technologies $6890 \mathrm{~N}$, Network GC System with A micro cell ${ }^{3} \mathrm{Ni}$ Electron Capture Detector ( $\mu \mathrm{ECD}$ ). For GC separation, a capillary column was used: RTX-5 (cross bonded 5\% diphenil-95\% diethyl polysiloxane) $15 \mathrm{~m} \times 0.25 \mathrm{~mm}$ ID $\times 0.25 \mu \mathrm{m} \mathrm{df}$, Restek Corp, Bellefonte, PA. The GC oven was held at $80^{\circ} \mathrm{C}$ for $1 \mathrm{~min}$ and then programmed at $10^{\circ} \mathrm{C} / \mathrm{min}$ to $180{ }^{\circ} \mathrm{C}$, followed by a $30^{\circ} \mathrm{C} / \mathrm{min}$ ramp to $300^{\circ} \mathrm{C}$. The temperature at the injection port was $250^{\circ} \mathrm{C}$. 
Calibration curves for GC- $\mu$ ECD were prepared with 1000 ppm standard solutions of TNT obtained from Restek Corp. Stock solutions of concentrations: 1, 0.5, 0.1, 0.05, 0.01 ppm diluted in HPLC grade acetonitrile (Sigma-Aldrich Chemical Co., Milwaukee) were prepared. All solutions were injected directly using glass syringes (Hamilton Series 7101) into the injection port, this analysis were carried out with three replicates for each concentration. Using TIJ method it was possible to generate standards samples with more uniform coverage, and one advantage is the fact that the surface loading concentration could be varied by changing the numbers of passes delivered to the sample without the need for serial dilutions. Fig. 23 shows the linear correlation of the variation of the number of passes for a $5292 \mathrm{ppm}$ solution. A direct relationship is observed.

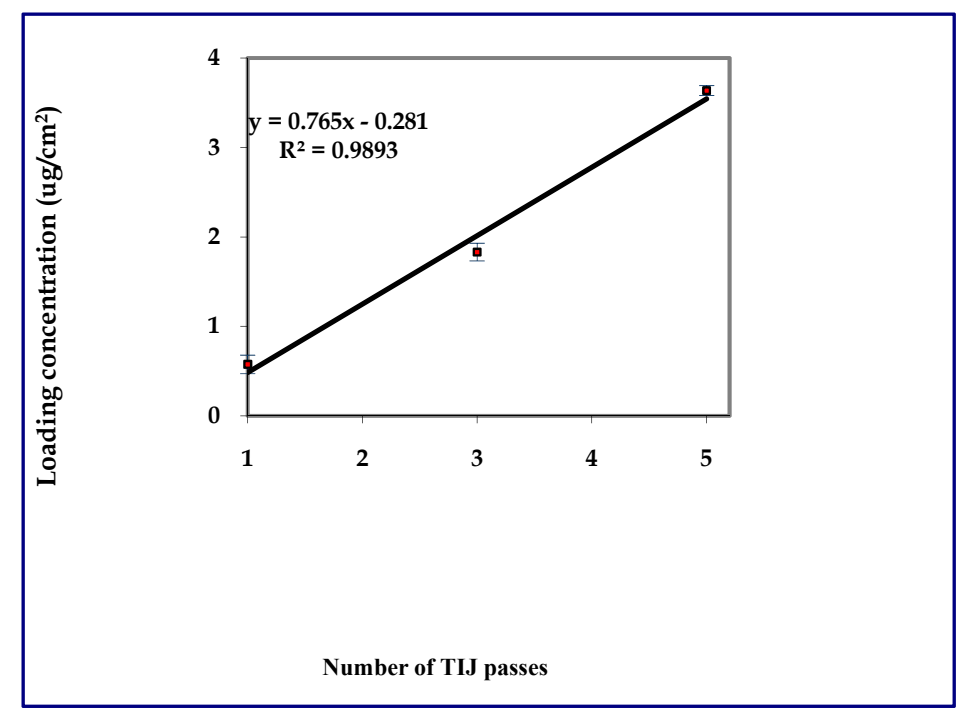

Fig. 23. Variation of the number of passes delivered to the surface for a TNT $5292 \mathrm{ppm}$ solution

For visualization of substrates after sample deposition, optical microscopy images were captured using Leica microscope (model LS). These images can be seen in Fig. 24. The images clearly reveal that TNT is collecting on the stainless steel surface as droplets and crystals. As the number of passes increases on the surface, the size of the droplets increases. At $1.25 \mu \mathrm{g} / \mathrm{cm}^{2}$ loading concentration, the surface is practically covered by crystals.

The way how the sample is distributed on the surface plays an important role in the task of calibrating the detection of the TNT or other compound on surfaces. To explore this effect, experiments were performed by positioning the probe head on different parts on the surface, and spectra were collected. Fig. 25 shows how the analytical response varies with the loading concentration. A peak-fitting model of the spectral region from approximately 1583-1396 and 1418-1220 $\mathrm{cm}^{-1}$ was fitted against each of the spectra in turn to give the total peak area for the selected region. This confirmed that although the coating is not homogenous a pattern with TIJ is generated, giving a few errors. 


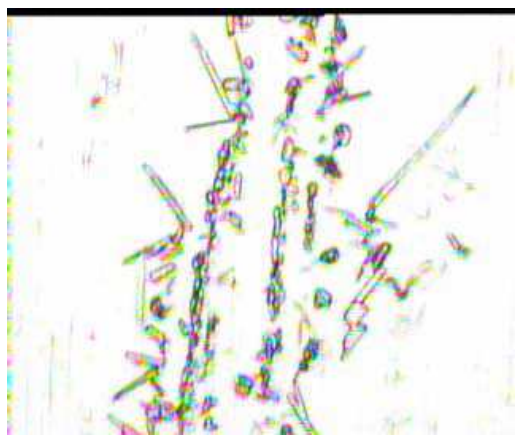

a. TNT $0.39 \mu \mathrm{g} / \mathrm{cm}^{2} 50 \mu \mathrm{m}$

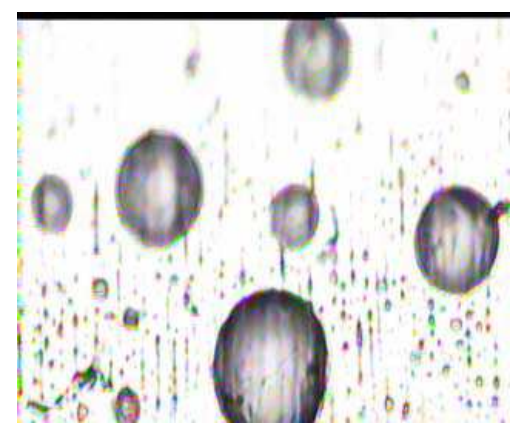

c. TNT $1.25 \mu \mathrm{g} / \mathrm{cm}^{2} 50 \mu \mathrm{m}$

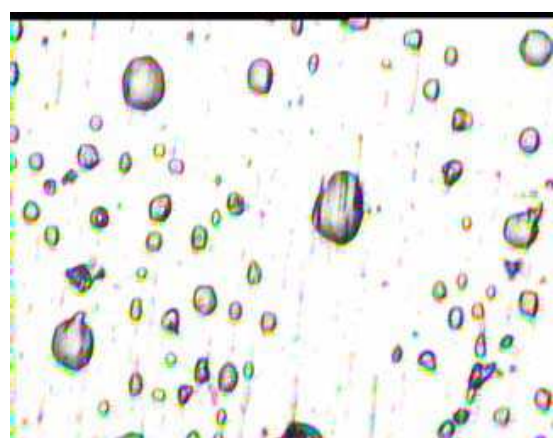

b. TNT $0.39 \mu \mathrm{g} / \mathrm{cm}^{2} 50 \mu \mathrm{m}$

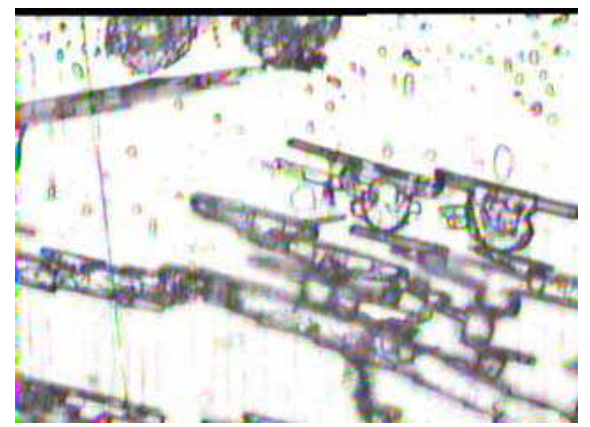

d. TNT $1.25 \mu \mathrm{g} / \mathrm{cm}^{2} 50 \mu \mathrm{m}$

Fig. 24. White light images of TNT deposits on stainless steel substrates using TIJ for deposition

The asymmetric and asymmetric vibrational stretches of the nitro $\left(\mathrm{NO}_{2}\right)$ group can be used for explosives detection since they act as vibrational signatures of several classes of explosives: nitroaromatic (TNT, DTNT), nitroaliphatic $\left(\mathrm{CH}_{3} \mathrm{NO}_{2}\right)$, nitramines (RDX, HMX) and nitrate esters (nitroglycerine, PETN). Fig. 26 shows the prominent signals of TNT deposited on stainless steel surfaces. All nitro signals were significant for quantitative and qualitative analysis. Nitro symmetric stretching vibration of TNT band appears at $1320-$ $1360 \mathrm{~cm}^{-1}$ and nitro asymmetric stretching vibration is typically located in the wavenumber range: 1477 - $1600 \mathrm{~cm}^{-1}$. A completely inverted spectrum with all bands pointing downwards is finally obtained for $1.73 \mu \mathrm{g} / \mathrm{cm}^{2}$ and $3.58 \mu \mathrm{g} / \mathrm{cm}^{2}$ loading concentration (Fig. 26). Fig. 27 shows TNT IRRAS spectra of two types of deposits. For very low surface loadings and for high surface concentrations $\left(3.58 \mu \mathrm{g} / \mathrm{cm}^{2}\right.$ shown in trace of Fig. 27-A), the typical downward looking percent transmission profiles are observed. However, IRRAS spectroscopic features of thins films on surfaces frequently show strongly variations of the relative intensities and wavelength shifts as the surface loadings changes. These effects were observed when the loading concentration of TNT was bellow $1.73 \mu \mathrm{g} / \mathrm{cm}^{2}$ (Fig. 27-B). Significant wavenumber shifts $\left(>10 \mathrm{~cm}^{-1}\right)$ were found for the nitro vibrations bands. An inverted upward looking profile similar to an absorption spectrum of the bands is clearly seen in lower trace in Fig. 


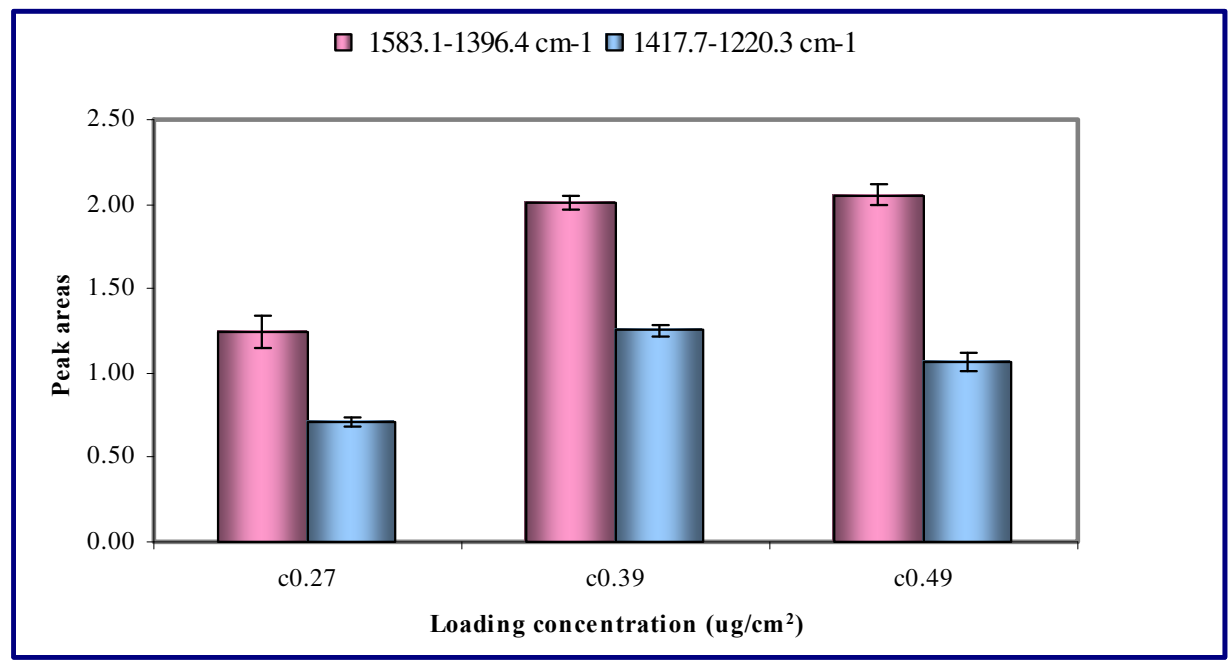

Fig. 25. Variation of the distribution of the TNT deposited on stainless steel using TIJ with the analytical response

The reflected radiation depends of the nature of the film as well as the incident angle of the IR beam reaching the surface. The properties of the reflected IR light depend critically on localized optical characteristics of the film such as the local index of refraction. Sample heterogeneities give rise to local changes in the refractive index across the sample and affect the reflectance spectra. Typical Infrared Reflection Absorption Spectroscopy (IRRAS) spectra are reported in terms the measured absorbance defined as (Bradshaw, 1988; Hayden, 1987):

$$
A=\log (\operatorname{Rr} / \operatorname{Rs})
$$

where: $\mathrm{Rr}$ is the reflectance of the of the plate (substrate) and Rs is the reflectance of the sample-substrate [22]. Fig. 26-A shows "normal" (vertical up) for low surface loadings (0.27- $\left.0.47 \mu \mathrm{g} / \mathrm{cm}^{2}\right)$. Fig. 26-B shows corresponding RAIS spectra for 1.73 and $3.58 \mu \mathrm{g} / \mathrm{cm}^{2}$ illustrating downward pointing peaks. Figs. 27-A and B contains expanded views in the wavenumber range for $\mathrm{Rr}$ and $\mathrm{Rs}$ of $0.27 \mu \mathrm{g} / \mathrm{cm}^{2}$ and $3.58 \mu \mathrm{g} / \mathrm{cm}^{2}$. The metallic substrate reflects more than the sample (TNT), it means that $\mathrm{Rr}>\mathrm{Rs}$ and a normal peak is found. This can be observed in Fig. 27-B. The inverted peak is found in 1561 because the difference between $\mathrm{Rr}$ and $\mathrm{Rs}$ in this frequency value is lower than in other values around this one in the frequency range $1548-1565 \mathrm{~cm}^{-1}$. This means that the sample is reflecting almost at the same level as the metal substrate. This fact can be explained based on changes in the refractive at the film-metallic surface interphase or by the way that TNT layers are packed on the surface. Another reason can be argued is the fact that these inverted bands are found when most of the coverage of the surface is TNT crystals and not amorphous TNT droplets.

It is very important to emphasize that measuring surface concentrations using the peak area method is conceptually simple and easy to use, but it has some limitations. The method is univariate: the concentration is determined with a single spectral peak and it 
depends on a linear correlation between the concentration and the spectral response. The results can, therefore, be undermined by perturbations such as fluctuations caused by detector noise, temperature variations, or molecular interactions. Statistically based, multivariate calibrations use spectral features over a wider range. Information from a calibration spectral set (a training set) was compared to independently determined concentration data using partial least squares regression (PLS). The method is based on the assumption that systematic variations in the spectra are a consequence of concentration changes.

a
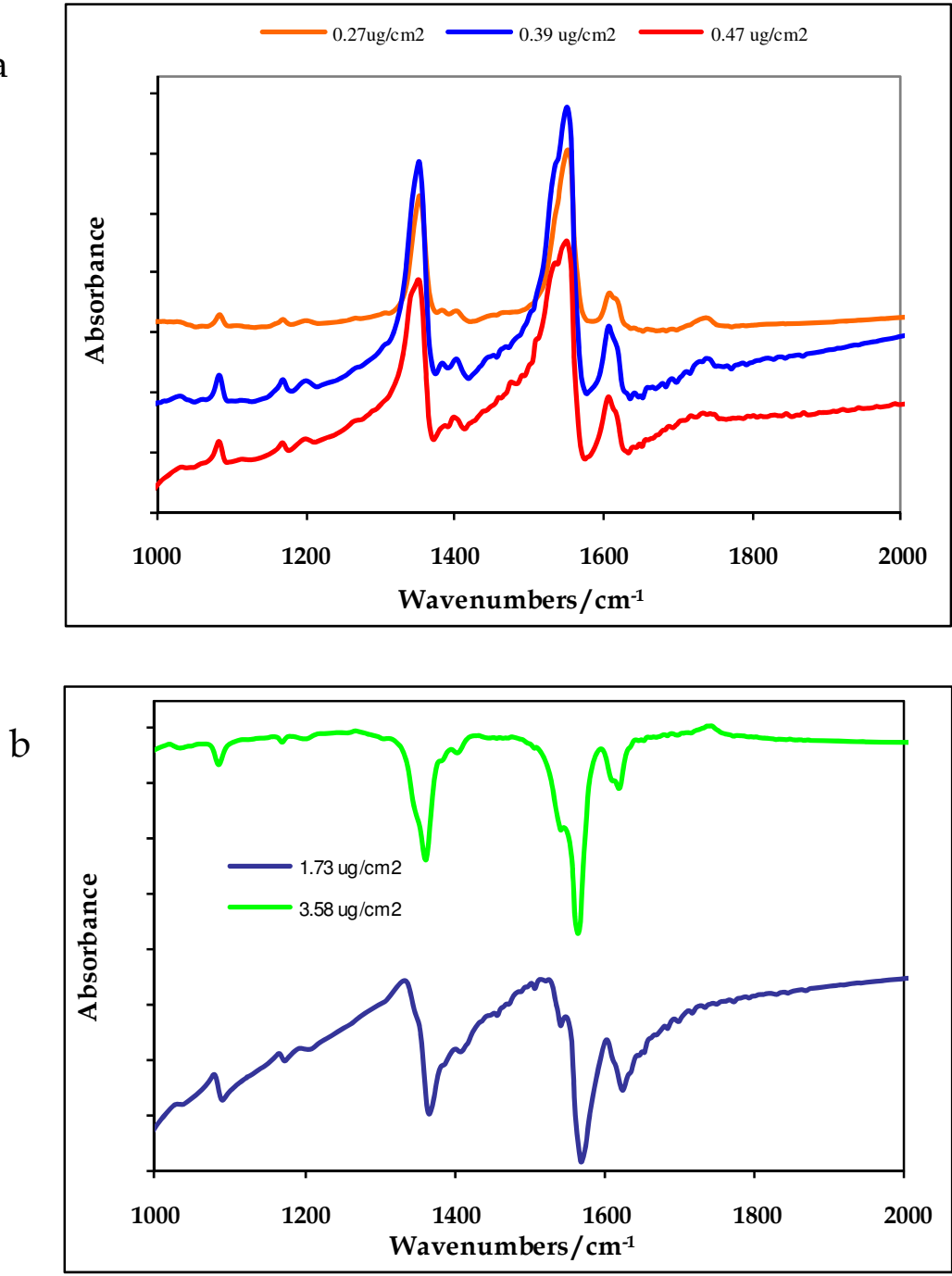

Fig. 26. Grazing angle spectra of TNT: a. Positive bands (normal). b. Inverted bands 

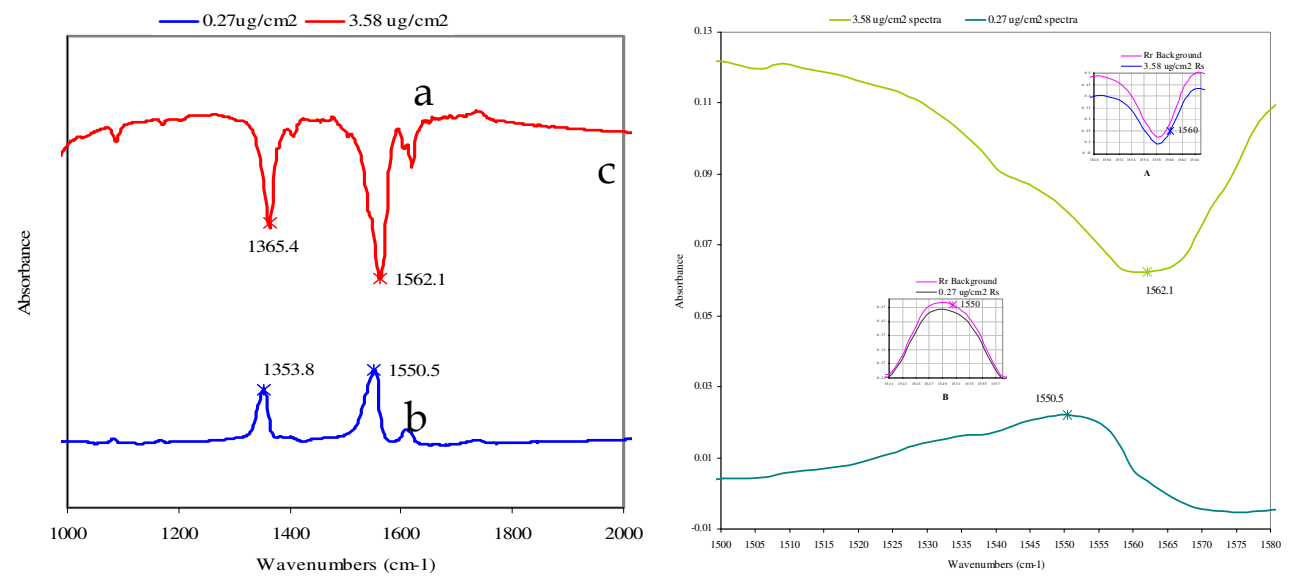

Fig. 27. IRRAS symmetric and asymmetric Nitro stretching vibrations of TNT a: normal (downward pointing) \% $\mathrm{T}$ profile; b: inverted (upward pointing) \% $\mathrm{T}$ profile; c: behavior of Rs and $\mathrm{Rr}$ for the peak formation

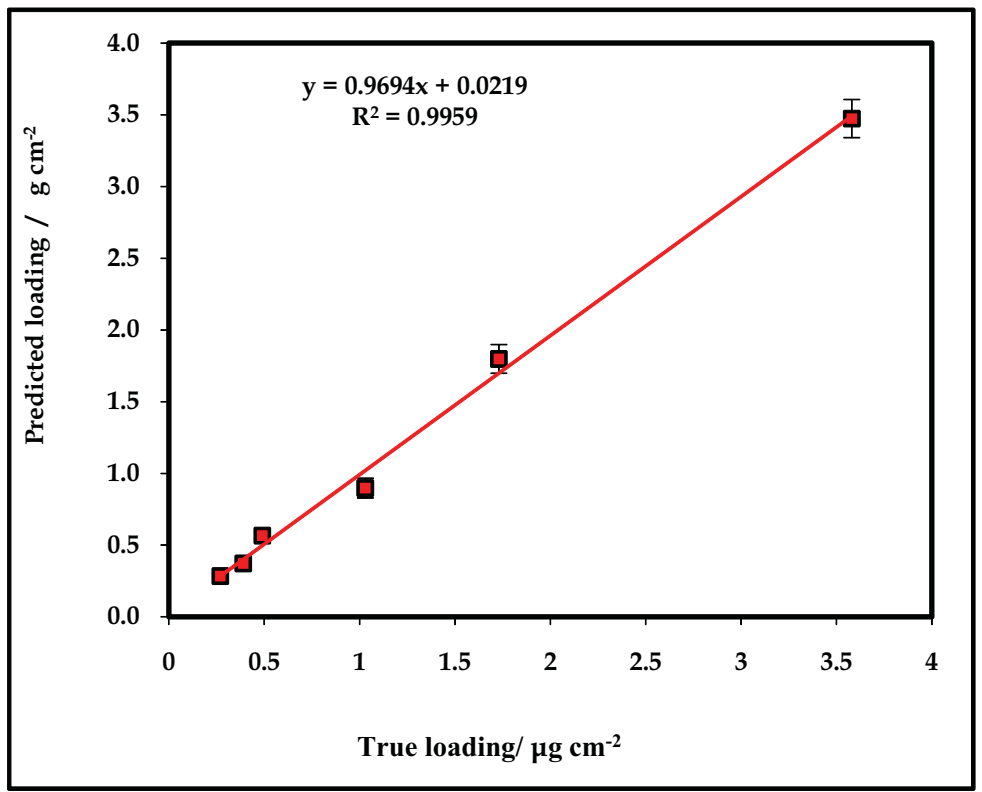

Fig. 28. Graph of averaged predicted surface loading values versus true values obtained by the "leave-one-out" cross validation of a Quant2 calibration for TNT on steel surfaces

Grazing angle FTIR spectra of prepared samples were collected for a series of different surface concentrations. When a PLS1 model was built from all of the 84 spectra listed, using the spectral region from 1028-1713 $\mathrm{cm}^{-1}$ and no spectral preprocessing, it was possible to build a calibration with $\mathrm{R}^{2}=0.9959$, and root mean square error of cross validation 
$($ RMSECV) $=0.258$ (obtained from a "leave-one-out" cross validation); the results are shown graphically in Fig. 28. According to these results TIJ-IRRAS combined with PLS can be used for TNT detection and quantification on metallic surfaces.

\section{Conclusion}

Fiber optic coupled FTIR spectroscopy has been shown to provide a useful technique for methods development for in situ detection explosives and active pharmaceutical ingredients and excipients on metallic surfaces. Very low detection limits $\left(\sim 0.3 \mu \mathrm{g} / \mathrm{cm}^{2}\right)$ were found for nitroexplosives and for organic peroxides. The present study was limited to highly reflective metallic surfaces such as stainless steel. However, since it is based on a grazing angle probe that is sensitive to adsorbates deposited on substrates regardless of the nature of the surface, and at least to first order, the methodology should be applicable for trace detection of explosives on other types of surfaces. The coupling of data acquisition to powerful non linear, multivariate analysis based on chemometrics routines such as partial least squares resulted in an even more robust analytical methodology. Explosives detection for this technique as applied to the target molecules used was found to be limited by the residence time of the substance on the surface. At low loading concentrations, high vapor pressure explosives escape to the vapor phase by sublimation even faster, limiting the low limit of detection achievable. The detection limit for TATP, high vapor pressure organic peroxide, was $8 \mu \mathrm{g} / \mathrm{cm}^{2}$. For nitroexplosives such as 2,6DNT, NG TNT, and PETN LODs found were $2.5,0.4,0.3$, and $0.3 \mu \mathrm{g} / \mathrm{cm}^{2}$ respectively. The results are in good agreement with a decreasing low limit of detection when arranged in the order of decreasing vapor pressure.

In this work we present the first method for detection and quantification of TATP on metallic surfaces. The method entails the coupling of optical fibers operating in the mid infrared (MIR) to a high performance interferometer. A grazing angle head coupled to liquid nitrogen cooled, MCT detector was used to excite and collect IR absorption spectra from stainless steel surfaces loaded with the organic peroxide. A smearing technique was used to prepare standards for surface loading of the explosive.

The novel aspects of the methodology involve in situ, remote sensed, fiber optic coupling of a grazing angle probe to a high sensitivity FTIR interferometer. It must be noted that the sample must to be measured immediately after the smearing to avoid sublimation of TATP from the metal surface. The robustness of the new methodology relies on utilizing powerful Chemometrics routines and Discriminant Analysis for statistical enhancement of data. Discriminant Analysis can be used to quantify TATP by classifying loading concentration in two groups: the first one corresponds to concentrations lower than $25 \mu \mathrm{g} / \mathrm{cm}^{2}$ and the second one to concentrations higher than $25 \mu \mathrm{g} / \mathrm{cm}^{2}$.

This work describes the first demonstration of a method for direct, in-situ detection and quantification of TATP on metallic surfaces. The rapid sublimation of TATP from the test surface has been demonstrated by tracking the decreasing intensities of the IR spectrum of TATP; the signal falls below the detection limit after about 9 minutes, from an initial value of $100 \mu \mathrm{g} / \mathrm{cm}^{2}$. This phenomenon limits the extent to which the surface concentration of TATP can be calibrated. However, it has been possible to show that TATP on metallic surfaces can be quantitatively detected in a matter of seconds using the grazing-angle FTIR approach. 
The first method for detection and quantification of TNT on metallic surfaces using thermal inkjet technology as a transfer method was discussed. Spectroscopic characterization and thin layer deposits quantification was achieved using the powerful Grazing Angle Probe Fiber Coupled-FTIR developed for surface analysis. Chemometrics routines were applied as data enhancers in order to accomplish fully the difficult task proposed. Inkjet printing of explosives demonstrated to have the following important characteristics: precision in sample deposit, drop delivery with non-contact fluid transfer and high reproducibility. The methodology could be applied for development of standards in Trace Explosive Reference materials on surfaces.

Sample transfer methods coupled to RAIRS promises to be an excellent support means when used as sensor for explosives detection on surfaces. A grazing angle head coupled to liquid nitrogen cooled, MCT detector was used to excite and collect IR absorption spectra from stainless steel surfaces loaded with the explosive. This case study suggests that MIR reflectance spectroscopy using a fiber-optic probe with grazing angle head is a viable method for detecting and measuring low $(\mu \mathrm{g} / \mathrm{cm} 2)$ quantities of organic contaminants on metallic surfaces. Adding chemometrics algorithms, which are developed and automated easily, leads to powerful techniques for surface contamination detection.

\section{Acknowledgments}

Parts of the work presented in this contribution were supported by the U.S. Department of Defense, University Research Initiative Multidisciplinary University Research Initiative (URI)-MURI Program, under grant number DAAD19-02-1-0257. The authors also acknowledge contributions from Mr. Aaron LaPointe from Night Vision and Electronic Sensors Directorate, Fort Belvoir, VA, Department of Defense, Dr. Jennifer Becker MURI Program Manager, Army Research Office, DoD and Dr. Stephen J. Lee Chief Scientist, Science and Technology, Office of the Director, Army Research Office/Army Research Laboratory, DoD.

Support from the U.S. Department of Homeland Security under Award Number 2008-ST061-ED0001 is also acknowledged. However, the views and conclusions contained in this document are those of the authors and should not be interpreted as necessarily representing the official policies, either expressed or implied, of the U.S. Department of Homeland Security.

Thanks are due to Dr. Luis. F De La Torre-Quintana for his assistance with statistical analysis and coupling with chemometrics routines and for his support and collaboration in design and preparation some figures.

\section{References}

Akhavan, J. (2004). The Chemistry of Explosives. 2nd ed. T J International Ltd, Padstow, Cornwall, UK,

Bacci, M.; Fabbri, M.; Picollo, M.; Porcinai, S. (2001). Non invasive fibre optic Fourier Transform-infrared reflectance spectroscopy on painted layers identification of materials by means of principal component analysis and Mahalanobis distance. Anal. Chim. Acta. 446, 15-21. 
Beebe, K.R.; Pell, R.J.; Seasholtz, M.B. (1998). Chemometrics: A Practical Guide; John Wiley \& Sons, Inc. New York, NY.

Beeson, R. and Skip, R.D., (1998). Thermal ink jet technology -review and outlook, Rung Research Laboratory, Inkjet Business Unit, Hewlett-Packard Company, Corvallis Oregon, US 3rd International Conference on Imaging Science. Chongqing, China.

Bellamy, A.J. (1999). Triacetone triperoxide: its chemical destruction. J. Forensic Sci. 44, 603608.

Blaudez, D.; Buffeteau, T.; Desbat, B.; Fournier, P.; Ritcey, A.; Pezolet, M. (1998). Infrared refection - absorption spectroscopy of thin organics films on nonmetallic substrates: optimal angle of incidence. J. Phys. Chem. B. 102, 99-105.

Bradshaw, A.M.; Schweitzer, E.; R.J.H. Clark.; Hester, R.E. (1988). Infrared reflection absorption spectroscopy of adsorbed molecules, in spectroscopy of surfaces. John Wiley $\mathcal{E}$ Sons, New York, NY.

Brambilla, G., Loizzo, A., Fontana, L., Strozzi, M., Guarino, A. and Soprano, V. (1997). J Am Med Assoc., 278, 635.

Demuth, H.; Beale, M. (1998). Neural Network Toolbox for use with MATLAB User's Guide Version 3.0; 5th ed.; The MathWorks, Inc., Natick, MA.

Diem, M. (1993). Introduction to Modern Vibrational Spectroscopy, John Wiley, New York, NY.

Evans, H.K.; Tulleners, F.A.J.; Sanchez, B.L.; Rasmussen, C.A. An Unusual Explosive, Triacetonetriperoxide (TATP). J. Forensic Sci. 1986, 31, 1119-1125.

Fierro-Mercado, P.M., Primera-Pedrozo, O.M., Hornedo, A., Hernández-Rivera, S.P., An In situ FTIR Fiber Optic Method for the Detection of Active Pharmaceutical Ingredients and Excipients on Metallic Substrates, in "Fourier Transform Infrared Spectroscopy: Developments, Techniques and Applications", Rees, O.J., ed., Chemical Engineering Methods and Technology Series, Nova Science Publishers, Inc. Hauppauge, NY, third quarter 2010, ISBN: 978-1-61668-835-6.

Griffiths, P.R. and De Haseth, J.A. (1986). Fourier- Transform Infrared Spectrometry. John Wiley, New York, NY.

Hamilton, M.L.; Perston, B.B.; Harland, P.W.; Williamson, B.E.; Thomson, M.A.; Melling, P.J. (2005). Org. Process Res. Devel. 9, 337-343.

Helmut, G.; Hans-Ulrich, G. (2002). IR Spectroscopy: An introduction. Wiley-VCH Federal Republic of Germany.

Hollins, P. (1992). The influence of surface defects on the infrared spectra of adsorbed species. Surf. Sci. Rep. 16, 51-94

Huberty, C. J. (1994). Applied Discriminant Analysis. Wiley-Interscience, NJ.

Hayden, B.E.; Yates, J.T.; Madey, T.E. (1987). Reflection Absorption infrared spectroscopy, in Vibrational Spectroscopy of molecules on surfaces. Vol. I. John Wiley \& Sons, New York, N.Y.

http://chesapeake.towson.edu/data/all_electro.asp

http://toxnet.nlm.nih.gov/cgi-bin/sis/htmlgen?HSDB.htm

http://www.wcer.wisc.edu/step/ep301/Spr2000/esselman/IBUb.html

Kaihara, M.; Sato, Y.; Sato, T.; Takahashi, T.; Takahashi, N. (2001). Chemometrics for FT-IR reflectance spectroscopy. The distinction between the specular and diffuse reflection. Analytical Sciences. 17, 1701-1704. 
Katona, Z.; Vincze, L.; Vegh, Z.; Trompler, A.; Ferenczi-Fodor, K. (2000). Cleaning validation procedure eased by using over pressured layer chromatographic. J. Pharmaceutical and Biomedical Analysis. 22, 349-353.

Kevin, J, Kochlowski.; Arbuckle-Keil, G. (2000). Infrared spectroscopy. Anal Chem. 72, 71$79 R$.

Kramer, R., (1998). Chemometric Techniques for Quantitative Analysis, Marcel Dekker, New York, NY.

Kurth, D. (1998). Analysis of artifacts in infrared spectroscopy of thin organic films on metallic substrates. Langmuir. 14, 6987-6991.

Lavine, B., and Workman, J. Jr. (2002). Chemometrics. Anal Chem. 74, 2763-2770.

Lin-Vien, D.; Colthup, N. B.; Fateley, W. G. and Grasselli, J. G. (1991).The Handbook of Infrared and Raman Characteristic Frequencies of Organic Molecules; Academic Press, San Diego, CA.

Mehta, N.K., Goenaga-Polo, J.E., Hernández-Rivera, S.P., and Hernández, D., Thomson, M.A. and Melling, P.J. (2002). Development of an In-Situ Spectroscopic Method for Cleaning Validation Using Mid-IR Fiber Optics. Bio Pharm. 15, 36-42.

Mehta, N.; Goenaga, J.; Hernandez-Rivera, S.P.; Hernandez, D.; Thomson, M.; Melling, P. (2002). Development of an in situ spectroscopic method for cleaning validation using mid-IR fiber optics. Spectroscopy. 18 (4),14-19.

Melling, P.J. and Shelley, P., (2001). Spectroscopic Accessory for Examining Films and Coatings on Solid Surfaces. U.S Patent 6,3,10,348, US Patent and Trademark Office, Washington, DC.

Melling, P, and Thomson, M. (2002). Fiber optic probes for mid-infrared spectrometry. John Wiley \& Sons Ltd., UK.

Mirza, T.; Lunn, M.; Keeley, F.; George, R.; Bodenmiller, J. (1999).Cleaning level acceptance criteria and high pressure liquid chromatography procedure for the assay of Meclizine Hydrochloride residue in swabs collected from pharmaceutical manufacturing equipment surfaces. Journal of Pharmaceutical and Biomedical Analysis. $19,747-756$.

Mizaikoff, B. (2002). Sensory Systems Based on Mid-infrared Transparent Fibers. In Handbook of Vibrational Spectroscopy, Vol. 2, Eds. Chalmers, J.M. and Griffiths, P.R. John Wiley \& Sons, Chichester, UK.

Nozal, M.; Bernal, J.; Toribio, L.; Martin, M.; Diez, F. (2001). Validation of a liquid chromatographic method for the determination of ranitidine hydrocloridine residues on surfaces in the manufacture of pharmaceuticals. J. Chromatogr. A. 919, 87-93.

Otto, M. (1999). Chemometrics. Statistics and Computer Application in Analytical Chemistry. Wiley-VCH. Federal Republic of Germany.

Pacheco-Londono, L., Santiago, A., Pujols, J., Primera-Pedrozo, O.M., Mattei, A., Ortiz, W., Ruiz, O., Ramirez, M., Hernandez-Rivera, S.P., (2007). Characterization of layers of Tetryl, TNB and HMX on metal surfaces using fiber optics coupled grazing angleFTIR. Proc. SPIE Int. Soc. Opt. Eng. 6542, 65423-65410.

Pacheco-Londoño, L.C., Primera-Pedrozo, O.M., Hernández-Rivera, S.P., (2010). Evaluation of Samples and Standards of Energetic Materials on Surfaces by Grazing AngleFTIR Spectroscopy in "Fourier Transform Infrared Spectroscopy: Developments, 
Techniques and Applications", Rees, O.J., ed., Chemical Engineering Methods and Technology Series, Nova Science Publishers, Inc. Hauppauge, NY, ISBN: 978-161668-835-6.

Primera-Pedrozo, O.M., Pacheco-Londono, L.C., De la Torre-Quintana, L.F., HernandezRivera, S.P., Chamberlain, R.T., Lareau, R.T. (2004). Use of fiber optic coupled FT-IR in detection of explosives on surfaces. Proc. SPIE Int. Soc. Opt. Eng. 5403, 237-245.

Primera-Pedrozo, O.M., Pacheco-Londoño, L., Ruiz, O., Ramirez, M., Soto-Feliciano, Y.M., De La Torre-Quintana, L.F., Hernandez-Rivera, S.P., (2005-a). Characterization of thermal Inkjet technology TNT deposits by fiber optic-grazing angle probe FTIR spectroscopy. Proc. SPIE Int. Soc. Opt. Eng. 543-552.

Primera-Pedrozo, O.M. (2005-b). MS Thesis, University of Puerto Rico, Mayaguez Campus, Mayaguez, PR.

Primera-Pedrozo, O.M., Rodriguez, N., Pacheco-Londono, L., Hernandez-Rivera, S.P., (2007). Detection of 2,4,6-trinitrotoluene on non-traditional surfaces using fiber optic coupled grazing angle probe-FTIR. Proc. SPIE Int. Soc. Opt. Eng. 6542, 6542365410.

Primera-Pedrozo, O., Soto-Feliciano, Y., Pacheco-Londoño, L., Hernández-Rivera, S. (2008). High Explosives Mixtures Detection Using Fiber Optics Coupled: Grazing Angle Probe/Fourier Transform Reflection Absorption Infrared Spectroscopy. Sens Imaging: Int. J. 9 (3), 27-40.

Primera-Pedrozo, O., Soto-Feliciano, Y., Pacheco-Londoño, L., Hernández-Rivera, S. (2009). Detection of High Explosives Using Reflection Absorption Infrared Spectroscopy with Fiber Coupled Grazing Angle Probe/FTIR. Sens Imaging: Int. J. 10 (1), 1-13.

Primera-Pedrozo, O.M., Soto-Feliciano, Y.M., Pacheco-Londoño, L.C., Hernández-Rivera, S.P., (2010). Fiber Optic-Coupled Grazing Angle Probe-Fourier Transform Reflection Absorption Infrared Spectroscopy for Analysis of Energetic Materials on Surfaces, in "Fourier Transform Infrared Spectroscopy: Developments, Techniques and Applications", Rees, O.J., ed., Chemical Engineering Methods and Technology Series, Nova Science Publishers, Inc. Hauppauge, NY, ISBN: 978-1-61668-835-6.

Salleras, L., Donguez, A., Mata, E., Taberrer, J.L., Moro, I. and Salva, P. (1995). Public Health Rep., Vol 110 pp338-342.

Schrader, B. (1995). Infrared and Raman spectroscopy: Methods and applications, Schrader, B., Ed. VCH, New York, NY, pp. 215.

Schulte-Ladbeck, R.; Kolla, P.; Karst U. (2003). Trace Analysis of Peroxide-Based Explosives. Anal. Chem. 75,731-735.

Schulte-Ladbeck, U, Karst. A field test for the detection of peroxide-based explosives. (2002). Analyst. 127, 1152-1154.

Statgraphics Plus for Windows (1999). Statistical graphics System, User's Guide version 3.0. Statistical Graphics Corporation.

Smith, B. Fundamentals of Fourier Transform Infrared Spectroscopy, CRC Press. Boca Raton, Florida, 2000.

Soto-Feliciano, Y., Primera-Pedrozo, O.M., Pacheco-Londono, L., Hernandez-Rivera, S.P., (2006). Temperature dependence of detection limits of TNT on metallic surfaces using fiber optic coupled FTIR. Proc. SPIE Int. Soc. Opt. Eng. 6201, 62012-62019. 
Urbanski, T. (1964). Chemistry and Technology of Explosives. Vol. 1, Macmillan Co.: New York, NY.

Zitrin, S.; Kraus, S.; Glasttstein, B. (1984). in: Proceedings of the International Symposium, US Government Printing Office, Washington, DC. pp 137-141.

White, G.M. (1992). An Explosive Drug Case. J. Forensic Sci. 37, 652-656. 


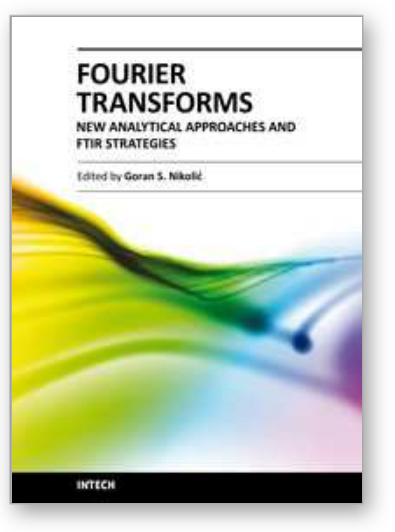

\author{
Fourier Transforms - New Analytical Approaches and FTIR \\ Strategies \\ Edited by Prof. Goran Nikolic
}

ISBN 978-953-307-232-6

Hard cover, 520 pages

Publisher InTech

Published online 01, April, 2011

Published in print edition April, 2011

New analytical strategies and techniques are necessary to meet requirements of modern technologies and new materials. In this sense, this book provides a thorough review of current analytical approaches, industrial practices, and strategies in Fourier transform application.

\title{
How to reference
}

In order to correctly reference this scholarly work, feel free to copy and paste the following:

Oliva M. Primera-Pedrozo, Leonardo C. Pacheco-Londoño and Samuel P. Hernandez-Rivera (2011). Applications of Fiber Optic Coupled-Grazing Angle Probe Reflection-Absorption FTIR Spectroscopy, Fourier Transforms - New Analytical Approaches and FTIR Strategies, Prof. Goran Nikolic (Ed.), ISBN: 978-953-307232-6, InTech, Available from: http://www.intechopen.com/books/fourier-transforms-new-analyticalapproaches-and-ftir-strategies/applications-of-fiber-optic-coupled-grazing-angle-probe-reflection-absorptionftir-spectroscopy

\section{INTECH}

open science | open minds

\author{
InTech Europe \\ University Campus STeP Ri \\ Slavka Krautzeka 83/A \\ 51000 Rijeka, Croatia \\ Phone: +385 (51) 770447 \\ Fax: +385 (51) 686166 \\ www.intechopen.com
}

\author{
InTech China \\ Unit 405, Office Block, Hotel Equatorial Shanghai \\ No.65, Yan An Road (West), Shanghai, 200040, China \\ 中国上海市延安西路65号上海国际贵都大饭店办公楼 405 单元 \\ Phone: +86-21-62489820 \\ Fax: +86-21-62489821
}


(C) 2011 The Author(s). Licensee IntechOpen. This chapter is distributed under the terms of the Creative Commons Attribution-NonCommercialShareAlike-3.0 License, which permits use, distribution and reproduction for non-commercial purposes, provided the original is properly cited and derivative works building on this content are distributed under the same license. 